\title{
ZnSe/N-doped Carbon Nanoreactor with multiple adsorption sites for Stable Lithium- Sulfur Batteries
}

Dawei Yang, Chaoqi Zhang*, Jordi Jacas Biendicho, Xu Han, Zhifu Liang, Ruifeng Du, Junshan Li, Jordi Arbiol, Jordi Llorca, Yingtang Zhou*, Joan Ramon Morante, Andreu Cabot*

D. W. Yang, C. Q. Zhang, Dr. J. J. Biendicho, Prof. J. R. Morante, Prof. A. Cabot Catalonia Institute for Energy Research - IREC

Sant Adrià de Besòs, Barcelona, 08930, Spain

Email: czhang@irec.cat, acabot@irec.cat

D. W. Yang, C. Q. Zhang, R. F. Du, Dr. J. S. Li, Prof. J. R. Morante

Department of Electronic and Biomedical Engineering

Universitat de Barcelona, 08028 Barcelona, Spain

X. Han, Z. F. Liang, Prof. J. Arbiol

Catalan Institute of Nanoscience and Nanotechnology (ICN2)

CSIC and BIST, Campus UAB, Bellaterra, 08193 Barcelona, Spain

Prof. J. Llorca

Institute of Energy Technologies, Department of Chemical Engineering and Barcelona

Research Center in Multiscale Science and Engineering

Universitat Politècnica de Catalunya, EEBE, 08019 Barcelona, Spain.

Prof. Y. T. Zhou

Key Laboratory of Health Risk Factors for Seafood and Environment of Zhejiang Province Institute of Innovation \& Application

Zhejiang Ocean University, Zhoushan, Zhejiang Province, 316022, China

Email: zhouyingtang@zjou.edu.cn

Prof. J. Arbiol, Prof. A. Cabot

ICREA

Pg. Lluís Companys 23, 08010 Barcelona, Spain

Keywords: Zinc selenide, multiple adsorption sites, catalytic effect, nanoreactor, lithium-sulfur batteries 


\begin{abstract}
The inhibition of this polysulfide shuttle effect and the promotion of the redox reaction kinetics remains as the key material challenges of lithium-sulfur batteries (LSBs) to be urgently solved. Here we report a new architecture for the cathode material based on nanoreactor of $\mathrm{ZnSe} / \mathrm{N}$ doped hollow carbon (ZnSe/NHC). This material combination and the hollow geometry provide three key benefits to the LSBs cathode: i) The combination of lithiophilic sites of NHC and sulfiphilic sites of ZnSe effectively trap LiPS as demonstrated by experimental results and density functional theory (DFT) calculations; ii) In part related to this promoted adsorption, the $\mathrm{ZnSe} / \mathrm{NHC}$ material combination is able to facilitate the $\mathrm{Li}^{+}$diffusion, thus promoting the redox reaction kinetics; iii) The hollow nanoreactor design traps LiPS and accommodates volumetric expansion preventing the cathode material decomposition. As a result, LSBs cathodes based on this hybrid material, S@ZnSe/NHC, are characterized by high initial capacities, $1475 \mathrm{mAh} \mathrm{g}^{-1}$ at $0.1 \mathrm{C}$ and $542 \mathrm{mAh} \mathrm{g}^{-1}$ at $3 \mathrm{C}$, and excellent rate capability. Besides, these cathodes deliver stable operation with only $0.022 \%$ capacity decay per cycle after 800 cycles at $3 \mathrm{C}$. Even at high sulfur loading of $3.2 \mathrm{mg} \mathrm{cm}^{-2}$, a reversible capacity of $540.5 \mathrm{mAh} \mathrm{g}^{-1}$ is delivered after 600 cycles at $1 \mathrm{C}$. Overall, this work not only further demonstrates the large potential of transitionmetal selenides as cathode materials in LSBs, but also demonstrates the nanoreactor design to be a highly suitable architecture to enhance cycle stability.
\end{abstract}




\section{Introduction}

Lithium-sulfur batteries (LSBs) have emerged as one of the most promising energy storage technologies owing to their potential low cost and high theoretical energy density $\left(2600 \mathrm{Wh} \mathrm{kg}^{-1}\right)$ compared to lithium-ion batteries $\left(420 \mathrm{Wh} \mathrm{kg}^{-1}\right) .{ }^{[1-3]}$ While large progress has been achieved in recent years, a number of challenges remain to be overcome to commercially realize their potential. First, the poor conductivity of sulfur and lithium sulfide results in a sluggish electron transport, which requires adding a high electrical conductivity support to the cathode. Besides, the severe volumetric expansion during lithiation causes the pulverization of the sulfur cathode and the detachment of part of the active material from the conducting framework, what calls for a strategy to contain the expansion and/or the active material. ${ }^{[4-6]}$ Additionally, the dissolution of intermediate lithium polysulfides (LiPS) into the electrolyte has associated a low coulombic efficiency (CE) and a rapid decline of capacity with cycling. Overcoming this limitation requires developing an efficient approach to immobilize the LiPS and enhance their redox kinetics. ${ }^{[7,8]}$

One effective strategy to improve the electrochemical performance of LSBs is to use carbon-based materials such as porous carbon, ${ }^{[9]}$ graphene, ${ }^{[10,11]}$ carbon spheres, ${ }^{[12]}$ carbon nanotubes, ${ }^{[13,14]}$ and nanofibers, ${ }^{[15]}$ as high electrical conductivity sulfur host at the cathode. However, while carbon materials facilitate electron transport and transfer at the cathode, they are not able to suppress polysulfide shuttling owing to the weak chemical interaction between nonpolar carbons and polar LiPS. ${ }^{[16,17]}$ Therefore, carbon-sulfur composites generally suffer from rapid capacity decays during cycling.

To promote interaction with LiPS, some polar inorganic materials have been recently considered as cathode materials, including transition metal oxides. ${ }^{[18,19]}$ hydroxides, ${ }^{[20]}$ carbides, ${ }^{[21]}$ nitrides, ${ }^{[22]}$ and sulfides. ${ }^{[23-25]}$ These polar materials offer abundant LiPS adsorption sites and can even accelerate the catalytic conversion of LiPS to sulfur and solid Li-S phases, $\mathrm{Li}_{2} \mathrm{~S}_{2} / \mathrm{Li}_{2} \mathrm{~S}$, thus strongly reducing the loss of sulfur. ${ }^{[26,27]}$ However, most metal oxides and sulfides have inherently poor electrical conductivities, which result in a low sulfur utilization efficiency and a sluggish redox reaction kinetics upon cycling.

Transition metal selenides (TMSe), such as $\mathrm{NiCo}_{2} \mathrm{Se}_{4}$ and $\mathrm{Sb}_{2} \mathrm{Se}_{3}$, are emerging as promising candidates to host sulfur at LSBs cathodes. ${ }^{[28,29]}$ Compared with oxides and sulfides, selenides are characterized by higher electrical conductivities, similar polarities and in some cases enhanced catalytic activities. However, owing to their relatively high volumetric density, 
TMSe need to be combined with high surface area carbon materials to achieve efficient utilization. In this direction, Zhang et al. recently demonstrated a graphene/CoSe $\mathrm{C}_{2}$ composited with superb electrocatalytic properties toward polysulfide redox reactions at triple-phase interfaces. ${ }^{[30]}$ To step further beyond the state of the art, the carbon support need to be optimized and the most suitable TMSe selected.

In terms of geometry, hollow structures and particularly hollow cages are a particularly interesting form of carbon. Hollow carbon materials can physically confine polysulfides, preventing the shuttle effect and promoting their conversion reaction. In terms of composition, the use of N-doped carbon can not only improve electrical conductivity, but also promote LiPS adsorption though $\mathrm{Li}-\mathrm{N}$ chemical binding. ${ }^{[31]}$ On the other hand, $\mathrm{Zn}$ compounds and particularly $\mathrm{ZnO}$ and $\mathrm{ZnS}$ have recently gained high interest as cathode material in LSBs owing to their good adsorption capability, notable catalytic activity toward polysulfide conversion and low cost. ${ }^{[32,33]}$

In this work, we hypothesize the yet unexplored selenide, $\mathrm{ZnSe}$, to be an optimum candidate as sulfur host in LSBs when combined with hollow N-doped hollow carbon. We detail here the first synthesis of $\mathrm{ZnSe}$ nanoparticles decorating $\mathrm{N}$-doped hollow polyhedrons (ZnSe/NHC). These particles are then tested as nanoreactors toward stable LSBs cathodes. The obtained results are rationalized with the help of density functional theory (DFT) calculations. 


\section{Results and discussion}

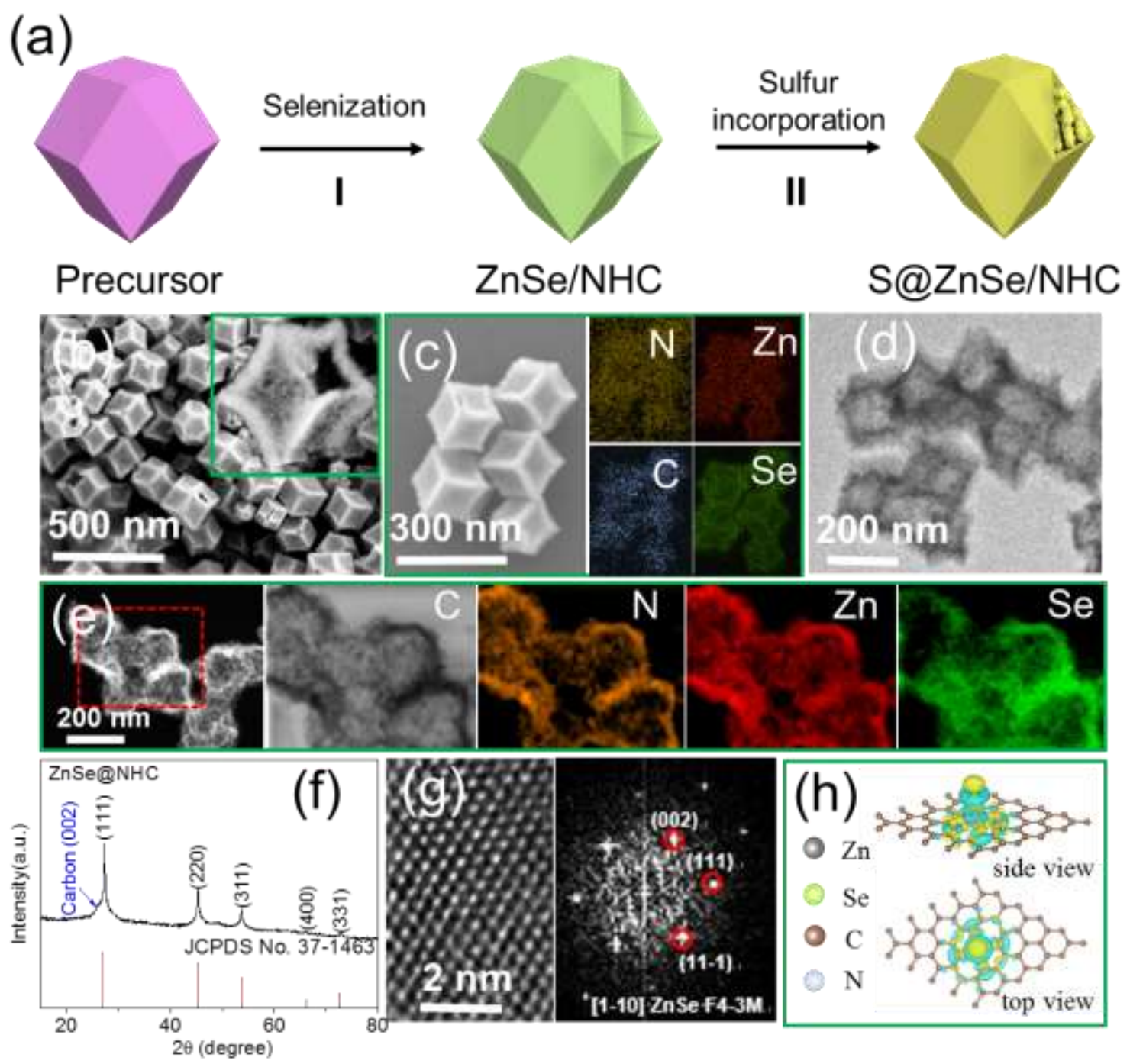

Figure 1. (a) Schematic illustration of the production of S@ZnSe/NHC composites. (b) FESEM image of ZnSe/NHC. Inset shows an enlarged hollow polyhedron. (c) SEM image and corresponding EDX elemental maps of N (yellow), Zn (red), C (blue), and Se (green). (d) TEM image of ZnSe/NHC. (e) STEM micrograph and corresponding EELS chemical composition maps. Individual C K-edge 284 eV (grey), N K-edge 401 eV (blue), Zn L 2,3 -edge 1020 eV (red), and $\mathrm{Se} \mathrm{L}_{2,3}$-edge $1436 \mathrm{eV}$ (green). (f) XRD pattern of $\mathrm{ZnSe} / \mathrm{NHC}$, including reference pattern for cubic ZnSe (JCPDS No. 37-1463). (g) HRTEM image of ZnSe/NHC and corresponding FFT spectrum. ZnSe lattice fringe distances were measured to be $0.317 \mathrm{~nm}, 0.321 \mathrm{~nm}$, and $0.285 \mathrm{~nm}$, at $67.48^{\circ}$ and $123.37^{\circ}$ which was interpreted as the ZnSe cubic phase visualized along its [1-10] 
zone axis. (h) Calculated charge density difference of $\mathrm{ZnSe} / \mathrm{NHC}$ from the model displayed in Figure S2. The yellow and blue regions represent increased and decreased electron density, respectively.

A schematic illustration of the process to produce $\mathrm{S} @ \mathrm{ZnSe} / \mathrm{NHC}$ is shown in Figure 1a. First, a ZIF-8 precursor powder with polyhedron-shaped particles was synthesized via a modified precipitation method (Supporting Information, Figure S1). In a second step, the obtained precursor was annealed in a Se atmosphere to produce $\mathrm{ZnSe} / \mathrm{NHC}$ (see experimental section for details). Finally, sulfur was incorporated within $\mathrm{ZnSe} / \mathrm{NHC}$ by means of a melt-diffusion process. SEM characterization revealed the $\mathrm{ZnSe} / \mathrm{NHC}$ particles display a polyhedral geometry with empty interiors as observed from some partially broken particles, EDS and TEM characterization (Figure 1b,c, d). We believe the hollow structure to be originated as a consequence of the different diffusion rates of selenium and zinc species through the growing ZnSe/NHC shells. This mechanism of formation of hollow particles is known as the nanoscale Kirkendall effect. ${ }^{[34,35]}$ EDS and EELS elemental maps showed C, N, Zn and Se to be homogenously distributed throughout the ZnSe/NHC cages (Figure 1c,e). XRD and HRTEM analyses showed the cubic ZnSe (JCPDS No.37-1463) as the only crystalline phase within ZnSe/NHC composites (Figure $1 \mathrm{f}, \mathrm{g}){ }^{[36,37]}$ DFT analysis of the electronic distribution within $\mathrm{ZnSe} / \mathrm{NHC}$ was analyzed by DFT showed electrons to be transferred from $\mathrm{ZnSe}$ to $\mathrm{NHC}$ and to accumulate around $\mathrm{N}$ atoms (Figure 1h), referring to model of the charge density difference of $\mathrm{ZnSe} / \mathrm{NHC}$ (Figure S2). This charge redistribution at the interface region might enhance electron mobility in the composite.

XPS survey analysis showed the presence of $\mathrm{Zn}$, Se, C, N and O in the surface of $\mathrm{ZnSe} / \mathrm{NHC}$ (Figure S3a). The presence of oxygen was attributed to the exposure of the sample to air during handling and transportation. ${ }^{[28,38]}$ XPS analysis also showed the material Fermi level to lay within a band of states, consistently with the metallic character of carbon (Figure S3f). The Zn 2p XPS spectrum (Figure S3b) exhibited one doublet at 1044.4 (Zn 2p $\mathrm{p}_{1 / 2}$ ) and 1021.4 eV (Zn $2 \mathrm{p}_{3 / 2}$ ) assigned to $\mathrm{Zn}^{2+}$ within a $\mathrm{ZnSe}$ chemical environment. ${ }^{[36,39]}$ The Se $3 \mathrm{~d}$ spectrum (Figure $\mathrm{S} 3 \mathrm{c})$ also displayed just one doublet at $54.7 \mathrm{eV}\left(\mathrm{Se} 3 \mathrm{~d}_{3 / 2}\right)$ and $53.8 \mathrm{eV}\left(3 \mathrm{~d}_{5 / 2}\right)$ associated to $\mathrm{Se}^{2-}$ within ZnSe. ${ }^{[40,41]}$ The high-resolution C 1s spectrum (Figure S3d) was fitted using four bands. The main band, at $284.8 \mathrm{eV}$, was associated to $\mathrm{C}-\mathrm{C}$ and it was used as reference. The $\mathrm{N} 1 \mathrm{~s}$ spectrum (Figure S3e) displayed three bands at 398.2, 399.6 and $400.7 \mathrm{eV}$, which were 
associated with pyridinic, pyrrolic and graphitic nitrogen, respectively. ${ }^{[42,43]}$ The detection of relatively large amounts of nitrogen confirmed the successful incorporation of nitrogen into the carbon framework. The presence of nitrogen within the carbon material was of interest for the potential of this element to increase the local atomic disorder, producing additional defects in carbon and exposing more active sites. Additionally, N-doping increases the electron concentrations, which could improve the electrical conductivity. ${ }^{[44,45]}$
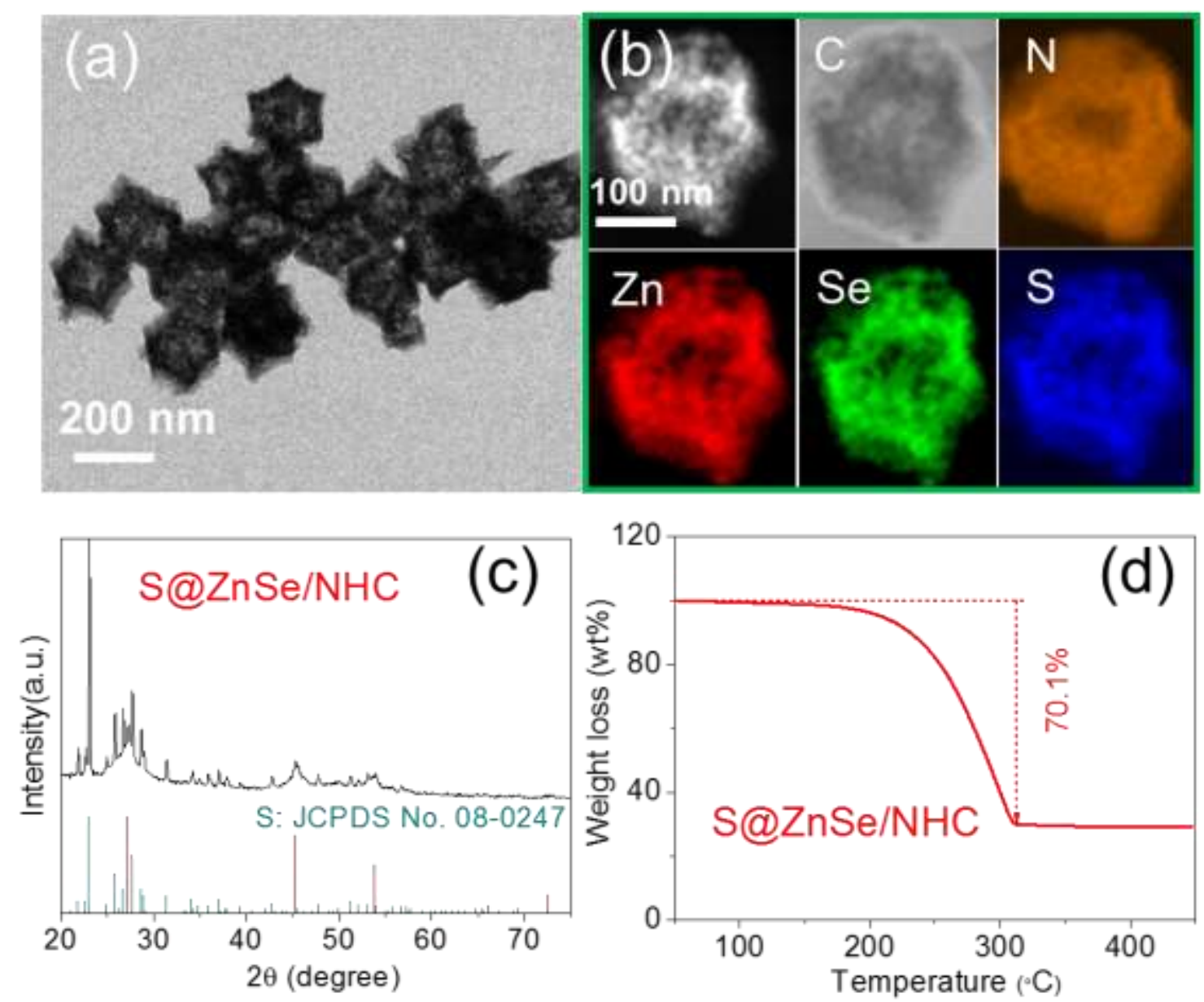

Figure 2. (a) Representative TEM image of a S@ZnSe/NHC composite. (b) STEM micrographs and corresponding EELS chemical composition maps. Individual C K-edge 284 eV (grey), N Kedge $401 \mathrm{eV}$ (orange), Zn L 2,3 -edge $1020 \mathrm{eV}$ (red), $\mathrm{Se} \mathrm{L}_{2,3}$-edge $1436 \mathrm{eV}$ (green), and S L $\mathrm{L}_{2,3}$-edge $165 \mathrm{eV}$ (blue). (c) XRD pattern of S@ZnSe/NHC, including reference patterns for cubic ZnSe (JCPDS No. 37-1463) and cubic sulfur (JCPDS No. 08-0247). (d) TGA curve of S@ZnSe/NHC composite. 
TGA analysis showed a mass decrease of ca. $70 \%$ when heating the sample up to $300{ }^{\circ} \mathrm{C}$, which was associated to the evaporation of sulfur and it was consistent with the nominal amount of sulfur introduced within $\mathrm{ZnSe} / \mathrm{NHC}$ (Figure. 2d). S@ZnSe/NHC particles maintained the polyhedral geometry of ZnSe/NHC and ZIF-8 but displayed a partially filled structure (Figure S4a). To further verify the presence of sulfur within the hollow structures, nitrogen adsorptiondesorption isotherms of the $\mathrm{ZnSe} / \mathrm{NHC}$ cages before and after sulfur incorporation were measured (Figure S4b, c). The Brunauer-Emmett-Teller (BET) specific surface area was $275 \mathrm{~m}^{2}$ $\mathrm{g}^{-1}$ for $\mathrm{ZnSe} / \mathrm{NHC}$, and decreased to $15.6 \mathrm{~m}^{2} \mathrm{~g}^{-1}$ for $\mathrm{S} @ \mathrm{ZnSe} / \mathrm{NHC}$. In parallel, the overall pore volume decreased from 0.29 to $0.05 \mathrm{~cm}^{3} \mathrm{~g}^{-1}$, with the sulfur incorporation. These results further suggested the partial filling of the internal cavities of $\mathrm{ZnSe} / \mathrm{NHC}$. We believe the partially filled and partially empty voids to be advantageous in terms of buffering the volume change and trap polysulfides during the charge/discharge process. ${ }^{[46]}$ Extensive TEM characterization discarded the presence of large sulfur aggregates outside the $\mathrm{ZnSe} / \mathrm{NHC}$ cages (Figure 2a). EELS elemental maps further demonstrated the homogeneous distribution of sulfur within the cages (Figure 2b). XRD patterns of S@ZnSe/NHC displayed the presence of additional peaks that were indexed as cubic sulfur (Figure 2c). ${ }^{[20]}$ 

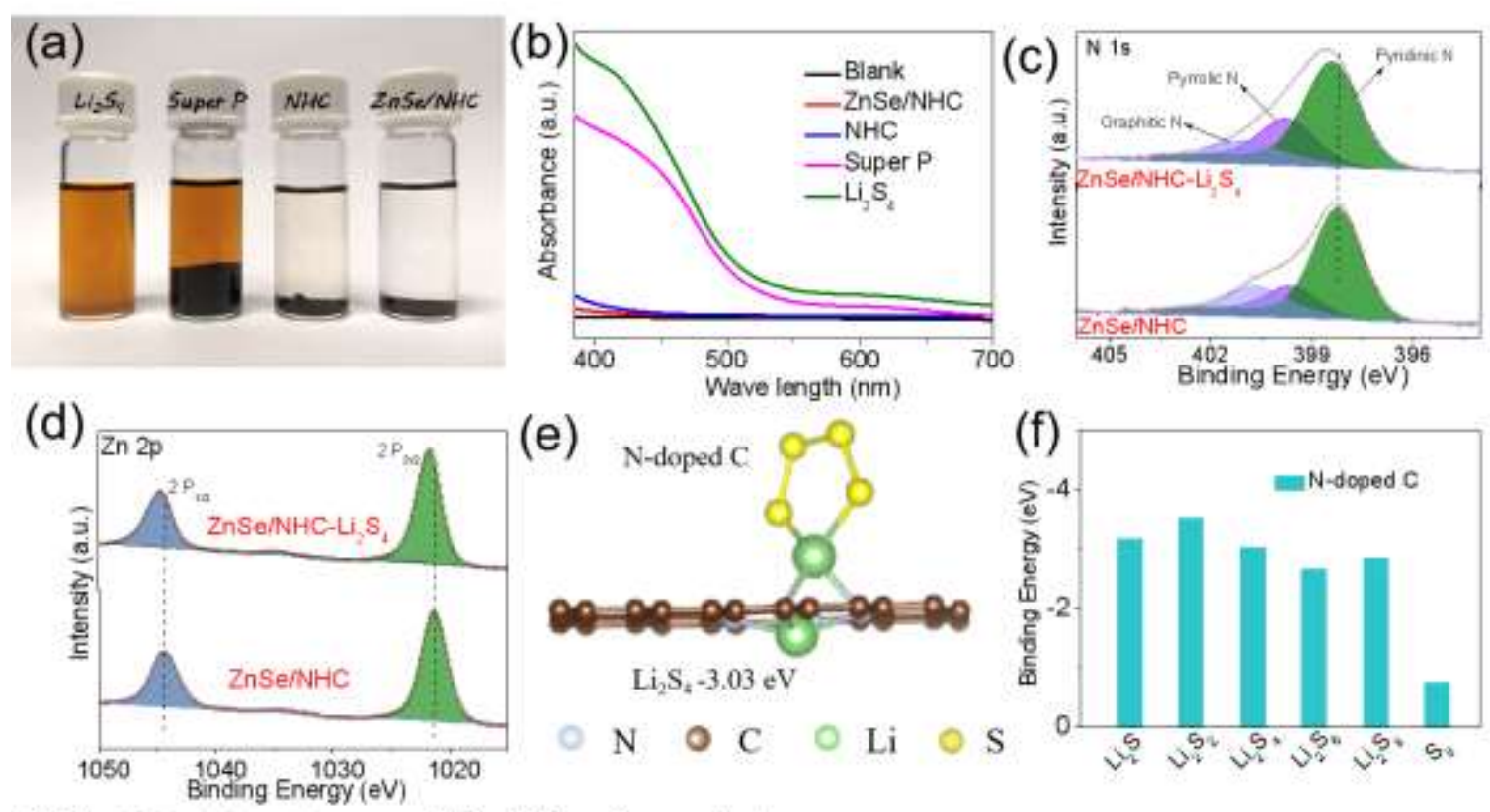

(g)
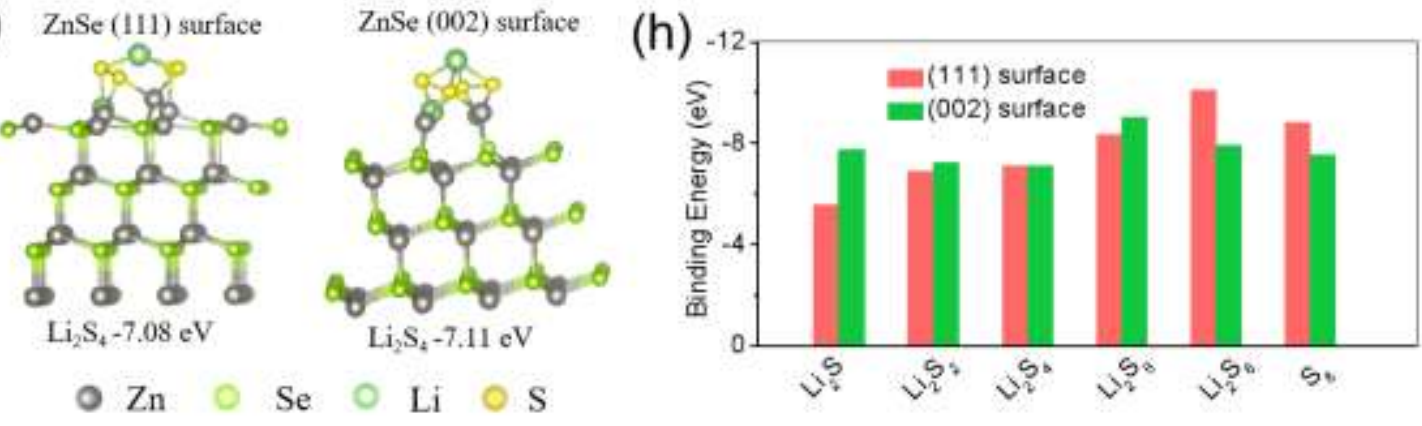

Figure 3. (a) Photograph of $\mathrm{Li}_{2} \mathrm{~S}_{4}$ solutions containing (from left to right and as indicated in the figure): no adsorbant, Super P, NHC and ZnSe/NHC. (b) UV-Vis spectra of the polysulfide solution after overnight mixing with the different adsorbents. A blank spectrum and the spectrum of the $\mathrm{Li}_{2} \mathrm{~S}_{4}$ solution not exposed to any adsorbant are also displayed. (c) $\mathrm{N}$ 1s and (d) $\mathrm{Zn} 2 \mathrm{p}$ XPS spectra of $\mathrm{ZnSe} / \mathrm{NHC}$ before and after adsorption of $\mathrm{Li}_{2} \mathrm{~S}_{4}$. (e) Adsorption configurations for $\mathrm{Li}_{2} \mathrm{~S}_{4}$ on a N-doped $\mathrm{C}$ surface. (f) Calculated binding energy between $\mathrm{LiPS}\left(\mathrm{Li}_{2} \mathrm{~S}, \mathrm{Li}_{2} \mathrm{~S}_{2}, \mathrm{Li}_{2} \mathrm{~S}_{4}\right.$, $\mathrm{Li}_{2} \mathrm{~S}_{6}, \mathrm{Li}_{2} \mathrm{~S}_{8}$ and $\mathrm{S}_{8}$ ) and the $\mathrm{N}$-doped $\mathrm{C}$ surface. (g) Optimized geometrical configurations of $\mathrm{ZnSe}$ with $\mathrm{Li}_{2} \mathrm{~S}_{4}$ on both (111) and (002) surfaces. (h) Binding energies for LiPS ( $\mathrm{Li}_{2} \mathrm{~S}, \mathrm{Li}_{2} \mathrm{~S}_{2}$, $\mathrm{Li}_{2} \mathrm{~S}_{4}, \mathrm{Li}_{2} \mathrm{~S}_{6}, \mathrm{Li}_{2} \mathrm{~S}_{8}$ and $\mathrm{S}_{8}$ ) on $\mathrm{ZnSe}$ surfaces calculated with DFT.

The $\mathrm{Li}_{2} \mathrm{~S}_{4}$ adsorption ability of the host material was tested to evaluate its potential to confine LiPS. Figure 3a displays optical images of vials that initially contained a $10 \mathrm{mM}$ 
solution of $\mathrm{Li}_{2} \mathrm{~S}_{4}$ and the same amount of $\mathrm{ZnSe} / \mathrm{NHC}$, Super P or NHC. After overnight mixing of the solutions, clear color differences were observed between the different vials. $\mathrm{The} \mathrm{Li}_{2} \mathrm{~S}_{4}$ solutions containing $\mathrm{ZnSe} / \mathrm{NHC}$ and NHC displayed a much paler color than the solution containing Super P. This faded color was associated to a much more effective adsorption of $\mathrm{Li}_{2} \mathrm{~S}_{4}$ on NHC and especially on ZnSe/NHC. UV-vis spectroscopy of the solution supernatants confirmed the notable differences of absorbance in the 400-500 nm region associated to $\mathrm{Li}_{2} \mathrm{~S}_{4}$, ${ }^{[47,48]}$ corroborating the different $\mathrm{Li}_{2} \mathrm{~S}_{4}$ adsorption ability of the various host materials (Figure $3 \mathrm{~b}$ ).

Figure 3c displays the high-resolution N 1s XPS spectrum of ZnSe/NHC before and after the $\mathrm{Li}_{2} \mathrm{~S}_{4}$ adsorption test $\left(\mathrm{ZnSe} / \mathrm{NHC}-\mathrm{Li}_{2} \mathrm{~S}_{4}\right)$. A clear shift of the $\mathrm{N} 1 \mathrm{~s}$ bands was observed with the $\mathrm{Li}_{2} \mathrm{~S}_{4}$ adsorption. We associate this shift with the binding of $\mathrm{Li}_{2} \mathrm{~S}_{4}$ and $\mathrm{N}$ heteroatoms. This binding takes place through a dipole-dipole electrostatic interaction between Li atoms having a Lewis acid character within LiPS and $\mathrm{N}$ heteroatoms with extra pair of electrons in carbon materials and a Lewis base character. ${ }^{[44,49]}$ This Li-N affinity provides NHC with a lithiophilic character that explains the high $\mathrm{Li}_{2} \mathrm{~S}_{4}$ adsorption ability of NHC. Figure $3 \mathrm{~d}$ displays the highresolution $\mathrm{Zn} 2 \mathrm{p}$ XPS spectrum of $\mathrm{ZnSe} / \mathrm{NHC}$ before and after the $\mathrm{Li}_{2} \mathrm{~S}_{4}$ adsorption test. A slight shift of the $\mathrm{Zn} 2 \mathrm{p}$ bands to higher binding energies was also observed after $\mathrm{Li}_{2} \mathrm{~S}_{4}$ adsorption. This shift was consistent with $\mathrm{Zn}$ being in a slightly more electronegative chemical environmental than within $\mathrm{ZnSe}$, which we associate with a chemical interaction between $\mathrm{Zn}$ and sulfur. This $\mathrm{Zn}-\mathrm{S}$ interaction, which adds up to the $\mathrm{N}-\mathrm{Li}$ interaction, explains the higher $\mathrm{Li}_{2} \mathrm{~S}_{4}$ adsorption ability of $\mathrm{ZnSe} / \mathrm{NHC}$ when compared with NHC.

DFT calculations were conducted to understand the chemical anchoring process at the atomic level. The geometries of the adsorption configurations for LiPS at six different lithiation stages on a N-doped C surface are displayed in Figure S5. The binding energy $\left(\mathrm{E}_{\mathrm{b}}\right)$ between LiPS species and $\mathrm{ZnSe} / \mathrm{NHC}$ was calculated to evaluate the LiPS adsorption capability. Figure 3e displays a configuration of a $\mathrm{Li}_{2} \mathrm{~S}_{4}$ molecule immobilized by $\mathrm{Li}-\mathrm{N}$ bonds on $\mathrm{N}$-doped $\mathrm{C}$ surface with a high $\mathrm{E}_{\mathrm{b}},-3.03 \mathrm{eV}$, suggesting a high lithiophilicity of $\mathrm{NHC}$ associated to the presence of $\mathrm{N}$. Several adsorption configurations with significantly higher $E_{b}$ than graphitic carbon demonstrated the affinity of N-doped C toward various LiPS species (Figure 3f). ${ }^{[50,51]}$

Several geometrically configurations of LiPS adsorbed at (111) and (002) facets of ZnSe are illustrated in Figure S6. Figure $3 \mathrm{~g}$ shows the calculated $\mathrm{E}_{\mathrm{b}}$ for $\mathrm{Li}_{2} \mathrm{~S}_{4}$ anchored on $\mathrm{ZnSe}(111)$ and 
(002) surfaces to be $-7.08 \mathrm{eV}$ and $-7.11 \mathrm{eV}$, respectively. The $\mathrm{E}_{\mathrm{b}}$ of additional LiPS adsorbed on the (111) and (002) surfaces of ZnSe are presented in Figure 3h.These DFT results demonstrated a strong interaction between $\mathrm{S}$ within LiPS and $\mathrm{Zn}$ within $\mathrm{ZnSe}$, which corroborates the sulfiphilic character of $\mathrm{ZnSe}$ within $\mathrm{ZnSe} / \mathrm{NHC}$. Overall, both experimental results and DFT calculations proved $\mathrm{ZnSe} / \mathrm{NHC}$ to have a high affinity toward LiPS, associated to the presence of a dual adsorption effect related to the presence of sulfiphilic sites on $\mathrm{ZnSe}$ and of lithiophilic sites on NHC.
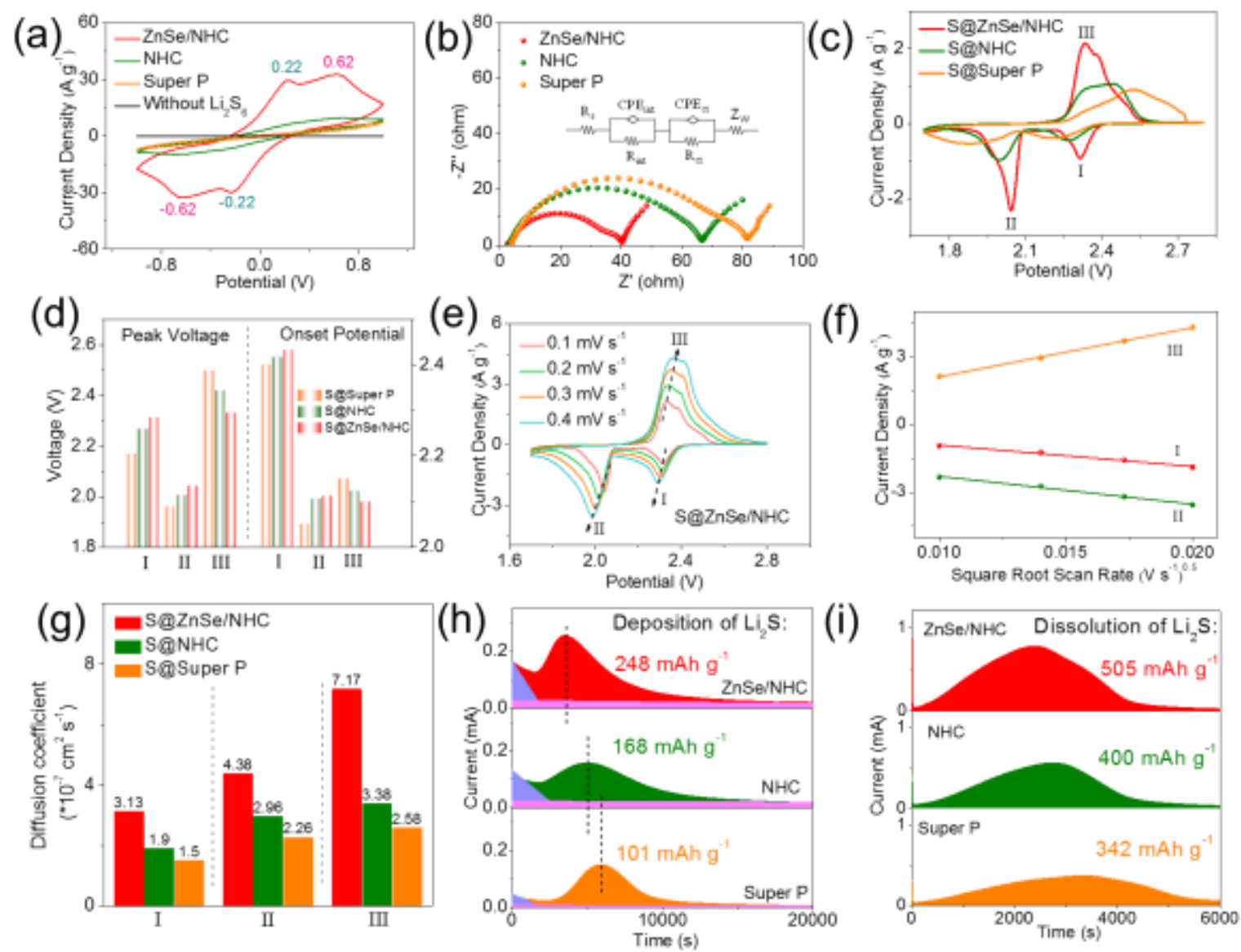

Figure 4. (a) CV curves at a scan rate of $20 \mathrm{mV} \mathrm{s}^{-1}$ of symmetrical cells using an electrolyte containing $0.5 \mathrm{~mol} \mathrm{~L}^{-1} \mathrm{Li}_{2} \mathrm{~S}_{6}$. (b) EIS curves of the same cells. Inset shows the fitted equivalent circuit. (c) CV curves of different electrodes at a scan rate of $0.1 \mathrm{mV} \mathrm{s}^{-1}$ within $1.7-2.8 \mathrm{~V}$ versus $\mathrm{Li} / \mathrm{Li}^{+}$. (d) Values of peak voltages and onset potentials of $\mathrm{Li}-\mathrm{S}$ cells obtained from the CV curves. (e) CV curves of a $\mathrm{S} @ \mathrm{ZnSe} / \mathrm{NHC}$ cathode at different scan rates. (f) CV redox peak current versus the square root of the scan rate. $(\mathrm{g}) \mathrm{Li}^{+}$diffusion coefficient calculated from the 
different CV redox peaks according to the Randles-Sevcik equation. (h) Potentiostatic discharge profiles with a $\mathrm{Li}_{2} \mathrm{~S}_{8}$ solution at $2.05 \mathrm{~V}$. (i) Potentiostatic charge profile at $2.40 \mathrm{~V}$ to evaluate dissolution kinetics of $\mathrm{Li}_{2} \mathrm{~S}$.

In order to study the electrocatalytic activity of the materials, $\mathrm{CV}$ curves were measured from symmetric cells made using $0.5 \mathrm{~mol} \mathrm{~L}^{-1} \mathrm{Li}_{2} \mathrm{~S}_{6}$ and $1 \mathrm{~mol} \mathrm{~L}^{-1}$ LiTFSI dissolved in DOL/DME ( $/ \mathrm{v}=1 / 1)$ as electrolyte and identical $\mathrm{ZnSe} / \mathrm{NHC}$ (NHC and Super P) electrodes as working and counter electrodes. To be able to eliminate the capacitive contribution, the CV of $\mathrm{ZnSe} / \mathrm{NHC}$ in a $\mathrm{Li}_{2} \mathrm{~S}_{6}$-free electrolyte was also measured as a reference (Figure $\mathrm{S7a}$ ). As shown in Figure 4a, ZnSe/NHC cells displayed two pairs of reversible redox peaks at a scan rate of 20 $\mathrm{mV} \mathrm{s}^{-1}$. During discharge process, the reduction peaks at $-0.22 \mathrm{~V}$ and $-0.62 \mathrm{~V}$ were related with the reduction of $\mathrm{S}$ to $\mathrm{Li}_{2} \mathrm{~S}_{6}$ and of $\mathrm{Li}_{2} \mathrm{~S}_{6}$ to $\mathrm{Li}_{2} \mathrm{~S}$, respectively. In the subsequent charge process, the oxidation peaks at 0.22 and $0.62 \mathrm{~V}$ corresponded to the oxidation of $\mathrm{Li}_{2} \mathrm{~S}_{\text {to }} \mathrm{Li}_{2} \mathrm{~S}_{6}$ and of $\mathrm{Li}_{2} \mathrm{~S}_{6}$ to $\mathrm{S}$, respectively. ${ }^{[1,26]} \mathrm{CV}$ curves of $\mathrm{ZnSe} / \mathrm{NHC}$ symmetric cells overlapped each other as shown for 10 cycles in Figure S7b, indicating an excellent reversibility. On the other hand, symmetric cells made of NHC and Super P-based electrodes exhibited much lower current densities and undefined redox peaks, demonstrating the essential role played by $\mathrm{ZnSe}$ in the electrochemical process (Figure 4a).

Results from EIS analysis of different symmetric cells after CV tests are displayed in Figure $4 \mathrm{~b}$. The equivalent circuit shown in the inset was used to fit Nyquist plots. The intersection of the curve with abscissa is assigned to the interphase-contact resistance of the electrolyte and the cells $\left(R_{s}\right)$. The first semicircle in the high frequency is related to the charge transfer resistance $\left(R_{c t}\right)$. The second semicircle in the middle frequency region is ascribed to the interface between the insulating layer of $\mathrm{Li}_{2} \mathrm{~S}$ and the electrode $\left(\mathrm{R}_{\text {int }}\right)$. Finally, the sloping lines in the low frequency region correspond to Warburg impedance $\left(Z_{\mathrm{w}}\right)$, which is related to the diffusion of lithium ions into the electrode. According to the fitting results (Figure S8), ZnSe/NHC cells delivered a lower $\mathrm{R}_{\mathrm{ct}}(40.1 \Omega)$ compared to NHC (67.8 $\Omega$ ) and Super P (81.5 $\left.\Omega\right)$, indicating enhanced charge and ion transfer, possibly due to their high conductivity. Besides, the $\mathrm{R}_{\text {int }}$ from the $\mathrm{ZnSe} / \mathrm{NHC}$ cell $(20.26 \Omega)$ was much smaller the measured from NHC (45.82 $\Omega$ ) and Super P $(65.82 \Omega)$. We associate this smaller $\mathrm{R}_{\text {int }}$ attributes to the uniform deposition of $\mathrm{Li}_{2} \mathrm{~S}$ on the surface of the electrodes. 
Tafel plot analysis further demonstrated $\mathrm{ZnSe} / \mathrm{NHC}$ electrodes to be characterized by a lower polarization potential and higher exchange current densities than the other electrodes, pointing toward an enhanced redox reaction kinetics in ZnSe/NHC (Figure S9).

Overall, the analysis of symmetric cells demonstrated that $\mathrm{ZnSe} / \mathrm{NHC}$ was characterized by significantly enhanced polysulfide redox kinetics enabled by a much faster charge transfer kinetics at the $\mathrm{ZnSe} / \mathrm{NHC} /$ polysulfide interface. ${ }^{[52-54]}$

CV curves of Li-S coin cells based on S@ZnSe/NHC cathodes are shown in Figure 4c. Data for the other electrodes with the same content of sulfur, S@NHC and S@Super P, can be found in Figure S10 and S11. CV curves measured from S@ZnSe/NHC cells almost overlaped during the first three cycles, implying a good reversibility of the sulfur redox reactions (Figure S12). S@ZnSe/NHC cathodes showed two representative cathodic peaks and one anodic peak. The two cathodic peaks (peak I and peak II) were associated with the reduction of $\mathrm{S}_{8}$ molecules to long-chain polysulfides (peak I) and to the further reduction to short-chain sulfides (peak II). The broad anodic peak (Peak III) was ascribed to the multistep oxidation of short-chain sulfides eventually to $\mathrm{S}_{8 .}{ }^{[23,52]}$ The $\mathrm{S} @ \mathrm{ZnSe} / \mathrm{NHC}$ cathode displayed a more positive potential of the cathodic peaks (peak I at 2.301 and peak II at $2.035 \mathrm{~V}$ ) and a more negative anodic peak (peak III at 2.355 V) than S@NHC and S@Super P (Figure 4d).

We further determined the onset potential as the potential required to reach a current density of $10 \mu \mathrm{A} \mathrm{cm}^{-2}$ beyond the baseline current as conventionally done in electrocatalysis (Figure S13 and 5d). ${ }^{[55,56]}$ We observed the cells based on S@ZnSe/NHC cathodes to display higher onset potentials of reduction peaks and lower onset potentials of oxidation peaks than cells based on other materials, which is consistent with the promotion of the polysulfide redox kinetics by the presence of $\mathrm{ZnSe} / \mathrm{NHC}$.

$\mathrm{CV}$ tests at different scan rates from 0.1 to $0.4 \mathrm{mV} \mathrm{s}^{-1}$ were conducted to investigate the electrode reaction kinetics and the lithium ion diffusion properties of S@ZnSe/NHC, S@NHC and S@Super P cathodes. As shown in Figure 4e, with the increase of the scan rates, the peak current density of the $\mathrm{S} @ \mathrm{ZnSe} / \mathrm{NHC}$ cathode increased, but its shape was maintained, denoting a good electrochemical stability. Besides, we observed a linear relationship between the cathodic and anodic peak currents and the square root of the scanning rate, as it corresponds to a diffusion-limited process (Figure 4f). From the fitting of this linear dependence, the diffusion 
constant of the rate limiting species, i.e. lithium ions $\left(D_{\mathrm{Li}+}\right)$, was calculated according to the Randles-Sevcik equation: ${ }^{[28,57]}$

$$
I_{\mathrm{p}}=\left(2.69 * 10^{5}\right) n^{1.5} A D_{L_{i+}}{ }^{0.5} C_{L i^{+}} v^{0.5}
$$

Equation 1

Where $I_{\mathrm{p}}$ is the peak current density, $\mathrm{n}$ is the number of charge transferred, $A$ is the geometric area of the electrode, $C_{\mathrm{Li+}}$ is the concentration of lithium ions in the cathode, and $v$ is the scan rate. According to the Randles-Sevcik equation, the values of $D_{\mathrm{Li}+}$ calculated for $\mathrm{S} @ \mathrm{ZnSe} / \mathrm{NHC}$ at peaks I, II, and III were $3.1 \times 10^{-7}, 4.4 \times 10^{-7}$, and $7.2 \times 10^{-7} \mathrm{~cm}^{2} \mathrm{~s}^{-1}$, respectively. Among the three materials tested, $\mathrm{S} @ \mathrm{ZnSe} / \mathrm{NHC}$ electrodes exhibited the sharpest slopes, thus the fastest lithium ion diffusion in both reduction and oxidation processes (Figure S14). The enhanced lithium ion diffusivity may be related to two aspects: i) a higher catalytic activity that lowers the energy barriers for electron transfer; and ii) a strong polysulfide adsorption that reduces the electrolyte viscosity, increasing mobility of electrolyte species and avoiding the deposition of an insulating layer.

To further explore catalytic properties of the cathode materials, the $\mathrm{Li}_{2} \mathrm{~S}$ nucleation and dissolution was studied through potentiostatic measurements. As observed in Figure 4h, the presence of $\mathrm{ZnSe}$ clearly resulted in shorter nucleation and growth times and a higher discharging peak current during the potentiostatic measurement at $2.05 \mathrm{~V}$. Based on the Faraday's law, the capacity of ZnSe/NHC electrodes was calculated at $248.2 \mathrm{mAh} \mathrm{g}^{-1}$, well above that of NHC (168.5 $\left.\mathrm{mAh} \mathrm{g}^{-1}\right)$ and Super P electrodes $\left(101.8 \mathrm{mAh} \mathrm{g}^{-1}\right)$. These results suggest that $\mathrm{ZnSe}$ significantly improved the kinetics of $\mathrm{Li}_{2} \mathrm{~S}$ precipitation. ${ }^{[30]}$ To study the kinetics of the $\mathrm{Li}_{2} \mathrm{~S}$ dissolution step, the potentiostatic cell charge at $2.40 \mathrm{~V}$ was analyzed (Figure 4i). ZnSe/NHC cathodes resulted in significantly higher current densities compared to NHC and Super $\mathrm{P}$, indicating its lower oxidation overpotential for $\mathrm{Li}_{2} \mathrm{~S}$ dissolution. ${ }^{[58.59]}$ Furthermore, the capacity of $\mathrm{Li}_{2} \mathrm{~S}$ dissolution of $\mathrm{ZnSe} / \mathrm{NHC}\left(505 \mathrm{mAh} \mathrm{g}^{-1}\right)$ was higher than NHC (400 $\mathrm{mAh} \mathrm{g}^{-1}$ ) and Super $\mathrm{P}\left(342 \mathrm{mAh} \mathrm{g}^{-1}\right)$.

After $20000 \mathrm{~s}$ potentiostatic discharge the coin cells were disassembled to further investigate the ability of $\mathrm{ZnSe} / \mathrm{NHC}$ in regulating the nucleation of $\mathrm{Li}_{2} \mathrm{~S}$. Interestingly, a layer of small $\mathrm{Li}_{2} \mathrm{~S}$ nanoparticles were uniformly distributed on the surface of $\mathrm{ZnSe} / \mathrm{NHC}$ (Figure S15a). In contrast, $\mathrm{Li}_{2} \mathrm{~S}$ nanoparticles aggregated on the surface of Super P, forming a bulky structure (Figure S15b). The differences in the morphology were mainly related to the large density of lithiophilic and sulfiphilic nucleation sites on the surface of $\mathrm{ZnSe} / \mathrm{NHC}$, which captured 
polysulfides and reduce the energy barrier of $\mathrm{Li}_{2} \mathrm{~S}$ nucleation. We believe this process significantly limited the shuttle effect. ${ }^{[30]}$

From the above results, it can be concluded that NHC and ZnSe with lithiophilic and sulfiphilic sites, respectively, are able to capture LiPS efficiently during redox reactions. The presence of $\mathrm{ZnSe}$ nanoparticles greatly boosts the reaction kinetics of LiPS.
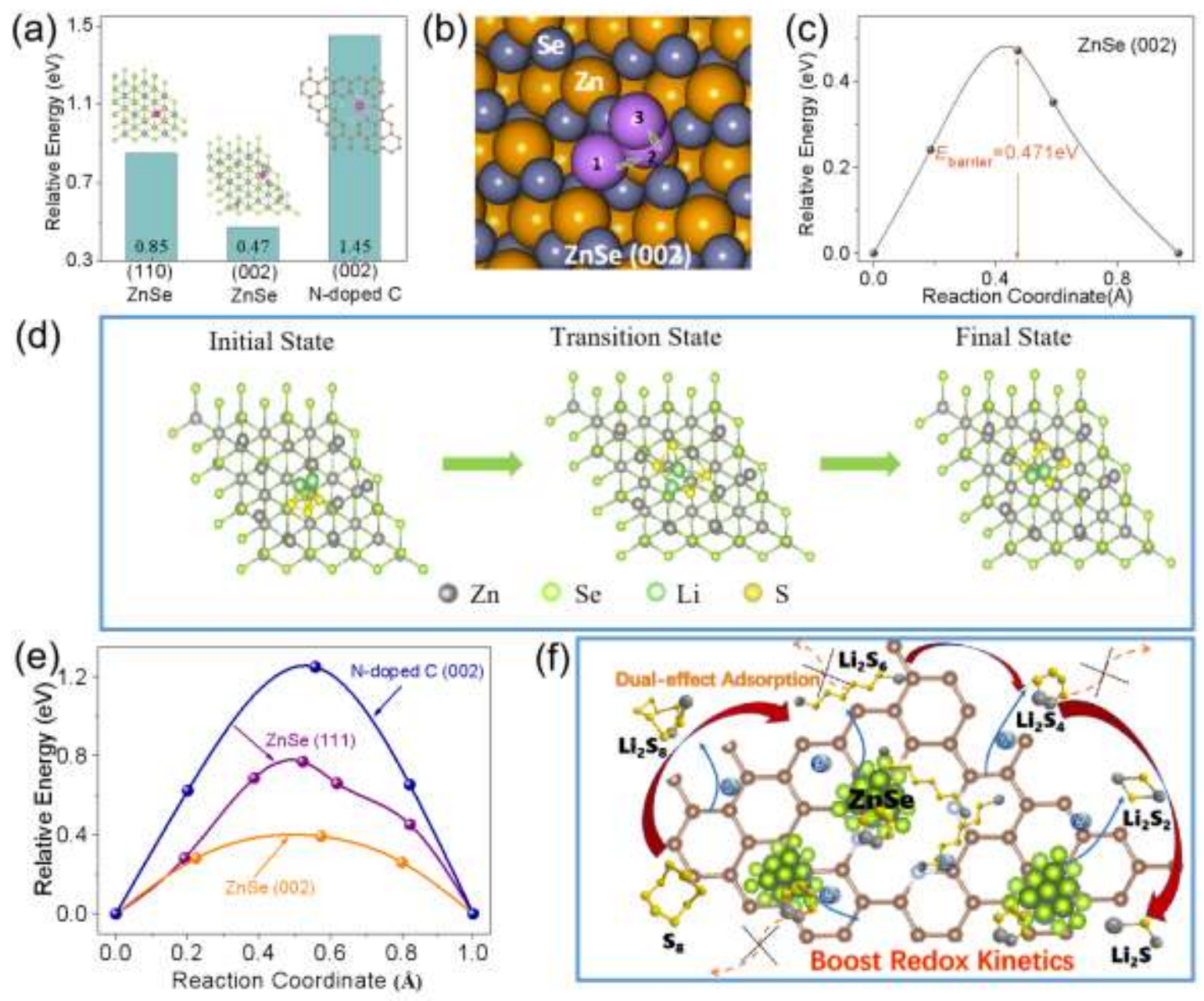

Figure 5. (a) Energy barrier of Li ion diffusion on (111) and (002) facets of ZnSe and (002) facet of N-doped C. (b) Geometrical configurations corresponded to the minimum energy path of Li ion diffusion on (002) facet of $\mathrm{ZnSe}$. 1, 2 and 3 represent initial state, transition state and final state, respectively. (c) Energy profile for Li ion diffusion on (002) facet at different adsorption sites. (d) Illustration of stages of $\mathrm{Li}_{2} \mathrm{~S}_{4}$ diffusing on a (002) facet of $\mathrm{ZnSe}$. (e) Energy profiles of $\mathrm{Li}_{2} \mathrm{~S}_{4}$ migration on (111) and (002) facets of $\mathrm{ZnSe}$ and (002) facet of $\mathrm{N}$-doped $\mathrm{C}$ along different 
adsorption sites. (f) Schematic illustration of the LiPS catalytic conversion on ZnSe during discharge process.

We further verified the boosted redox kinetics of LiPS catalytic conversion by DFT calculations. Figure 5a, S16 and S17 show the minimum energy barrier ( $\mathrm{E}_{\text {barrier }}$ ) of Li ion diffusion on three facets, suggesting Li ion diffused fastest on the (002) facet of ZnSe than on the other two facets. The schematic diagram of Li ion diffusion on (002) facet is displayed in Figure 5b. Figure 5c and S18 exhibit the $\mathrm{E}_{\text {barrier }}$ of Li ion diffusion for different adsorption sites of the three facets. It was concluded that $\mathrm{ZnSe}$ diffuses fastest on the (002) facet, suggesting that the presence of $\mathrm{ZnSe}$ accelerates the diffusion of Li ion. Figure 5d, S19 and S20 show the initial state, transition state and final state of $\mathrm{Li}_{2} \mathrm{~S}_{4}$ migration on the three facets. The $\mathrm{E}_{\text {barrier }}$ of $\mathrm{Li}_{2} \mathrm{~S}_{4}$ migration along different adsorption sites shown in Figure 5e and Figure S21 (Supporting Information). The $\mathrm{E}_{\text {barrier }}$ for $\mathrm{Li}_{2} \mathrm{~S}_{4}$ migration was calculated to be $0.392,0.771$ and $1.25 \mathrm{eV}$ on (002), (111) and N-doped C surfaces, respectively. These results confirmed that ZnSe facilitated the migration of $\mathrm{Li}_{2} \mathrm{~S}_{4}$. During the reaction process, LiPS species were anchored through the lithiophilic sites of NHC and sulfiphilic sites of ZnSe. This dual adsorption not only effectively suppressed the shuttle effect, but also accelerated the diffusion of $\mathrm{Li}^{+} / \mathrm{LiPS}$, thereby enhancing the LiPS conversion reaction kinetics (Figure 5f). 

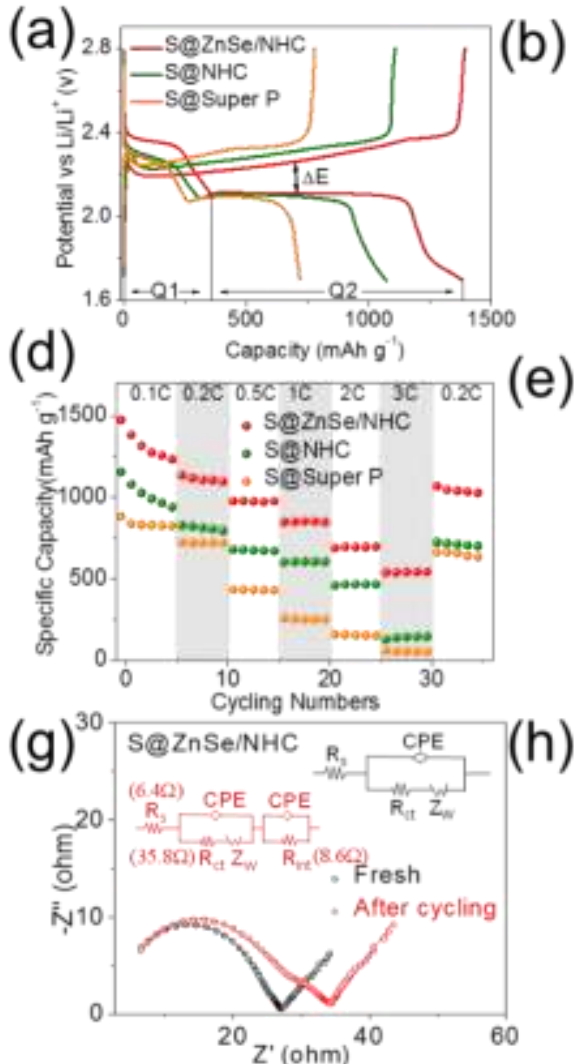

(e)
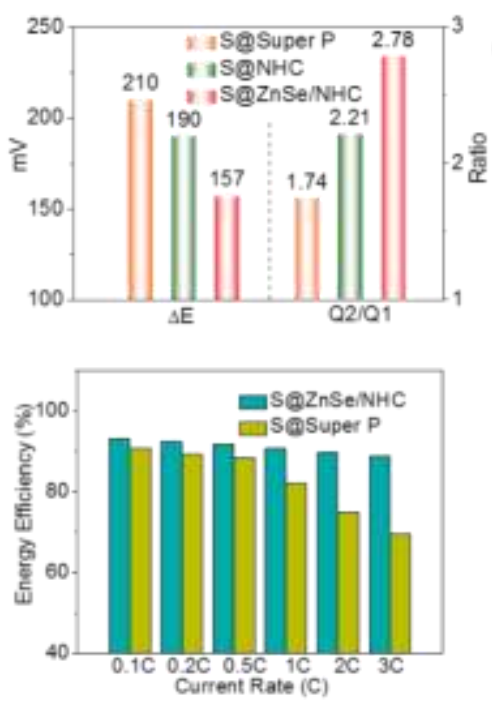

(f)
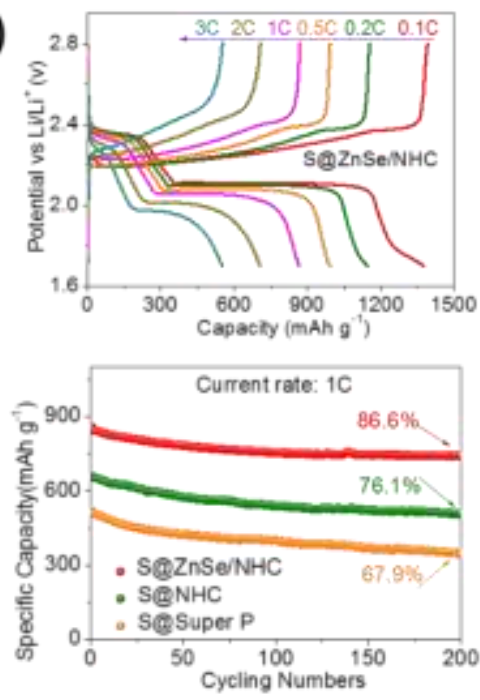

(h)
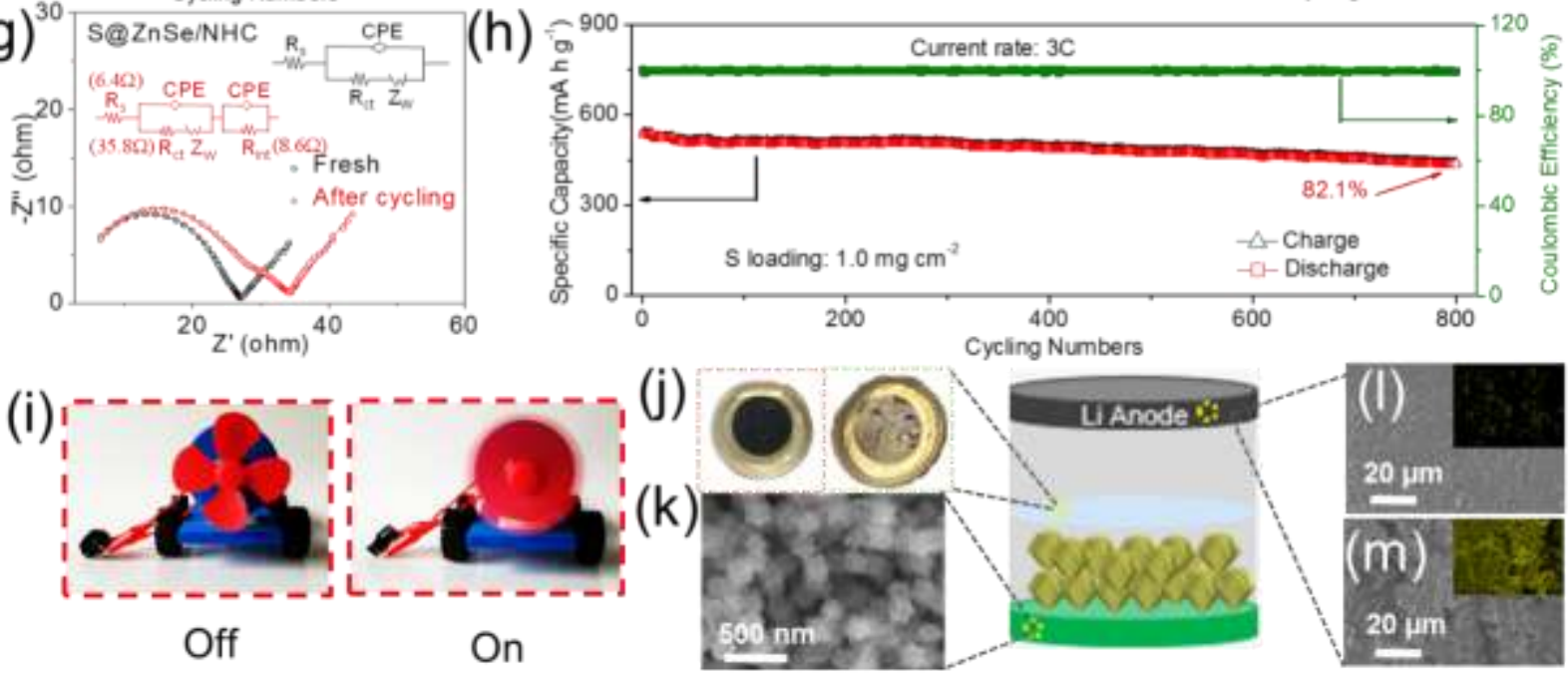
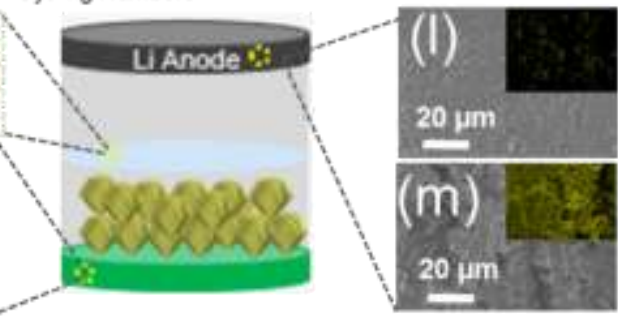

Figure 6. (a) Galvanostatic charge-discharge profiles of different electrodes at a current density of 0.1 C. (b) $\Delta \mathrm{E}$ and $\mathrm{Q} 2 / \mathrm{Q} 1$ calculated from the charge-discharge curves. (c) Galvanostatic charge-discharge profiles of $\mathrm{S} @ \mathrm{ZnSe} / \mathrm{NHC}$ at different current densities range from $0.1 \mathrm{C}$ to $3 \mathrm{C}$. (d) Rate capabilities of different electrodes at various current densities. (e) Energy efficiency of S@ZnSe/NHC compared with S@Super P. (f) Cycling life of various cathodes after 200 cycles at 1 C. (g) EIS spectrum of $\mathrm{S} @ \mathrm{ZnSe} / \mathrm{NHC}$ cathode before and after 200 cycles at $1 \mathrm{C}$. (h) Cycling performances and corresponding CEs of S@ZnSe/NHC cathode at a high current rate of 3 C. (i) Digital photographs of wind car powered by one $\mathrm{S} @ \mathrm{ZnSe} / \mathrm{NHC} \mathrm{Li}-\mathrm{S}$ coin cell. (j) Separators of coin cells with S@ZnSe/NHC as cathode (left) and S@Super P as cathode (right) after cycling at $1 \mathrm{C}$ for 200 cycles. (k) SEM image of S @ZnSe/NHC cathode and $(1, \mathrm{~m})$ surface 
of lithium foil from S@ZnSe/NHC and S@Super P coin cells. Inset images in $(1, \mathrm{~m})$ are EDX mapping images showing sulfur signal after cycling.

Electrochemical performance was further analyzed through galvanostatic charge-discharge tests. Figure 6a shows the charge-discharge curves of S@ZnSe/NHC, S@/NHC and S@Super P at a current density of $0.1 \mathrm{C}$. Charge-discharge curves displayed two discharge plateaus and one charge plateau. The voltage difference between the oxidation and the second reduction plateaus is the polarization potential, referred as $\Delta \mathrm{E} . \mathrm{S} @ \mathrm{ZnSe} / \mathrm{NHC}$ showed lower polarization potential $(\Delta \mathrm{E}=157 \mathrm{mV})$ than $\mathrm{S} @ \mathrm{NHC}(\Delta \mathrm{E}=190 \mathrm{mV})$ and $\mathrm{S} @$ Super P electrodes $(\Delta \mathrm{E}=210 \mathrm{mV})$ as displayed in Figure 6b. ${ }^{[20,49]}$ The first discharge plateau around $2.3 \mathrm{~V}$ is related to the reduction of sulfur to soluble LiPS $\left(\mathrm{S}_{8} \rightarrow \mathrm{S}_{6}{ }^{2-} \rightarrow \mathrm{S}_{4}{ }^{2-}\right)$. The second discharge plateau, at about $2.1 \mathrm{~V}$, corresponds to the conversion of soluble LiPS to lithium sulfide $\left(\mathrm{S}_{4}{ }^{2-} \rightarrow \mathrm{Li}_{2} \mathrm{~S}_{2} \rightarrow \mathrm{Li}_{2} \mathrm{~S}\right)$. ${ }^{[22,28]}$ Defining Q1 and Q2 as the capacity of the first and second discharge plateaus, respectively, the ratio Q2/Q1provides an idea of the material catalytic activity. ${ }^{[28]}$ The higher $\mathrm{Q} 2 / \mathrm{Q} 1$, the better the catalytic ability, because Q1 measures the amount of soluble polysulfides created and potentially diffusing to the Li metal anode, while Q2 measures how efficiently polysulfides are reduced to $\mathrm{Li}_{2} \mathrm{~S} .{ }^{[60,61]}$ As shown in Figure 6b of the Q2/Q1 ratio for $\mathrm{S} @ \mathrm{ZnSe} / \mathrm{NHC}$ was 2.68, well above the values obtained from S@NHC and S@Super P, 2.05 and 1.64,respectively. The high Q2/Q1 ratio further confirmed the superior catalytic activity towards polysulfides redox reaction of ZnSe/NHC. ${ }^{[60]}$ The enhanced electrochemical kinetics of S@ZnSe/NHC compared with other electrodes was also in accordance with the lower measured overpotentials for phase conversion between the soluble LiPS and insoluble $\mathrm{Li}_{2} \mathrm{~S}_{2} / \mathrm{Li}_{2} \mathrm{~S}$ during the discharge (Figure S22a) and charge (Figure S22b) processes.

The galvanostatic charge-discharge voltage profiles of S@ZnSe/NHC at various current densities range from 0.1 to $3 \mathrm{C}$ are presented in Figure $6 \mathrm{c}$, two discharge plateaus and one charge plateau were clearly maintained at the various current rates tested, which is in contrast to results obtained from S@NHC and S@Super P (Figure S23). A high initial specific capacity of 1475 $\mathrm{mAh} \mathrm{g}^{-1}$ was delivered by the $\mathrm{S} @ \mathrm{ZnSe} / \mathrm{NHC}$ electrode. Additionally, a superior rate performance of this electrode compared was inferred from the average discharge capacities of 1340, 1116, 977, 852, 696 and $542 \mathrm{mAh} \mathrm{g}^{-1}$ at current rates from $0.1 \mathrm{C}$ to $3 \mathrm{C}$, respectively, which are well above than those obtained from S@NHC and S@ Super P (Figure 6d). Even when the current density was returned to $0.2 \mathrm{C}$, the specific capacity of the $\mathrm{S} @ \mathrm{ZnSe} / \mathrm{NHC}$ electrode 


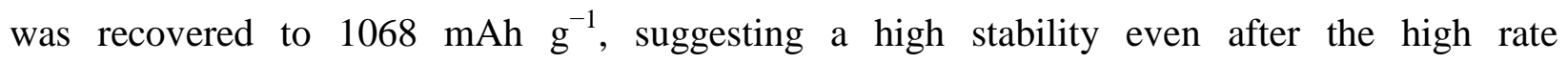
charge-discharge process.

As shown in Figure 6e, cells based on S@ZnSe/NHC were also characterized by higher energy efficiencies, $E=\int U I d t$, compared to S@Super P. Energy efficiency is a key parameter in energy storage devices, ${ }^{[28]}$ as it determines energy losses during charging/discharging process, especially at high current rates. The significant enhancement in energy efficiency obtained from $\mathrm{ZnSe} / \mathrm{NHC}$ cells stemmed from the lower polarization potential, associated with the exceptional catalytic properties of the cathode material.

The cycling performance of different cathodes was evaluated at a current density of $1 \mathrm{C}$ (Figure 6f). S@ZnSe/NHC electrodes displayed an initial high specific capacity of $858.7 \mathrm{mAh}$ $\mathrm{g}^{-1}$. After 200 cycles, $86.6 \%$ of the capacity was still retained, $826.9 \mathrm{mAh} \mathrm{g}^{-1}$. In contrast, the S@NHC cathode presented a discharge capacity of $657.8 \mathrm{mAh} \mathrm{g}^{-1}$ after 200 cycles $(76.1 \%$ retention), and the S@Super P cathode showed a capacity of only $516.1 \mathrm{mAh} \mathrm{g}^{-1}$ after 200 cycles (67.9\% retention). The higher capacity loss in these cathodes was in large part associated to the rapid dissolution of polysulfides into the electrolyte.

Figure $6 \mathrm{~g}$ presents results from the EIS analysis of the S@ZnSe/NHC cathode before the first discharge and after 200 cycles modeled with equivalent circuits. It can be seen clearly from the fresh cells that the first semicircle in the high frequency is related to the charge transfer resistance $\left(\mathrm{R}_{\mathrm{ct}}\right)$ and a linear dependence in the low frequency region that reflected the diffusion of lithium ions into the electrode. Compared with S@NHC (50.2 $\Omega$ ) and S@Super P (98.5 $\Omega$ ), $\mathrm{S} @ \mathrm{ZnSe} / \mathrm{NHC}$ electrodes showed the lowest $\mathrm{R}_{\mathrm{ct}}(28.6 \Omega)$, which means ZnSe/NHC can facilitate charge transfer, favoring the rapid polysulfide conversion reactions. ${ }^{[29,62]}$ While after 200 cycles, another semicircle in the middle frequency region appears resulted from the deposition of the insulating layer of $\mathrm{Li}_{2} \mathrm{~S}$ on the electrode surface $\left(\mathrm{R}_{\mathrm{int}}\right)$. S@ZnSe/NHC electrodes have a considerably lower $\mathrm{R}_{\text {int }}(8.6 \Omega)$ than $\mathrm{S} @ \mathrm{NHC}(35.6 \Omega)$ and $\mathrm{S} @ \operatorname{Super} \mathrm{P}(68.3 \Omega$ ) (Figure S24), may attributing to the introduction of $\mathrm{ZnSe}$ that catalyze the conversion reactions of polysulfides, thus suppressing the formation of an insulating layer of solid $\mathrm{Li}_{2} \mathrm{~S}_{2} / \mathrm{Li}_{2} \mathrm{~S}$ on the surface of electrodes.

Even at a high current rate of $3 \mathrm{C}, \mathrm{S} @ \mathrm{ZnSe} / \mathrm{NHC}$ electrodes displayed stable cycling performance with an average $0.022 \%$ capacity decay per cycle after 800 cycles and CEs above 99.5\% (Figure 6h). Under the same electrochemical conditions, pure ZnSe/NHC electrodes 
showed a negligible capacity (Figure S25). To further demonstrate the potential of $\mathrm{S} @ \mathrm{ZnSe} / \mathrm{NHC}$ cathodes for practical applications, a wind car was powered by one $\mathrm{S} @ \mathrm{ZnSe} / \mathrm{NHC}$ coin cell, as displayed in Figure 6i.

Coin cells were disassembled after 200 cycles at 1 C. As shown in Figure 6j, after 200 cycles the separator from $\mathrm{S} @ \mathrm{ZnSe} / \mathrm{NHC}$ cells exhibited lighter color than that from $\mathrm{S} @$ Super $\mathrm{P}$, which indicated that $\mathrm{ZnSe} / \mathrm{NHC}$ blocked the diffusion of LiPS more effectively. ${ }^{[25]}$ Besides the S@ZnSe/NHC cathode material maintained its original morphology after 200 cycles, demonstrating its excellent structural stability during lithiation/delithiation processes (Figure 6k). In addition, the lithium metal foils from S@ZnSe/NHC showed fewer sulfur signals and less corrosion than those from S@Super P, as displayed by SEM and EDX mapping in Figure 6(1, m). [48]

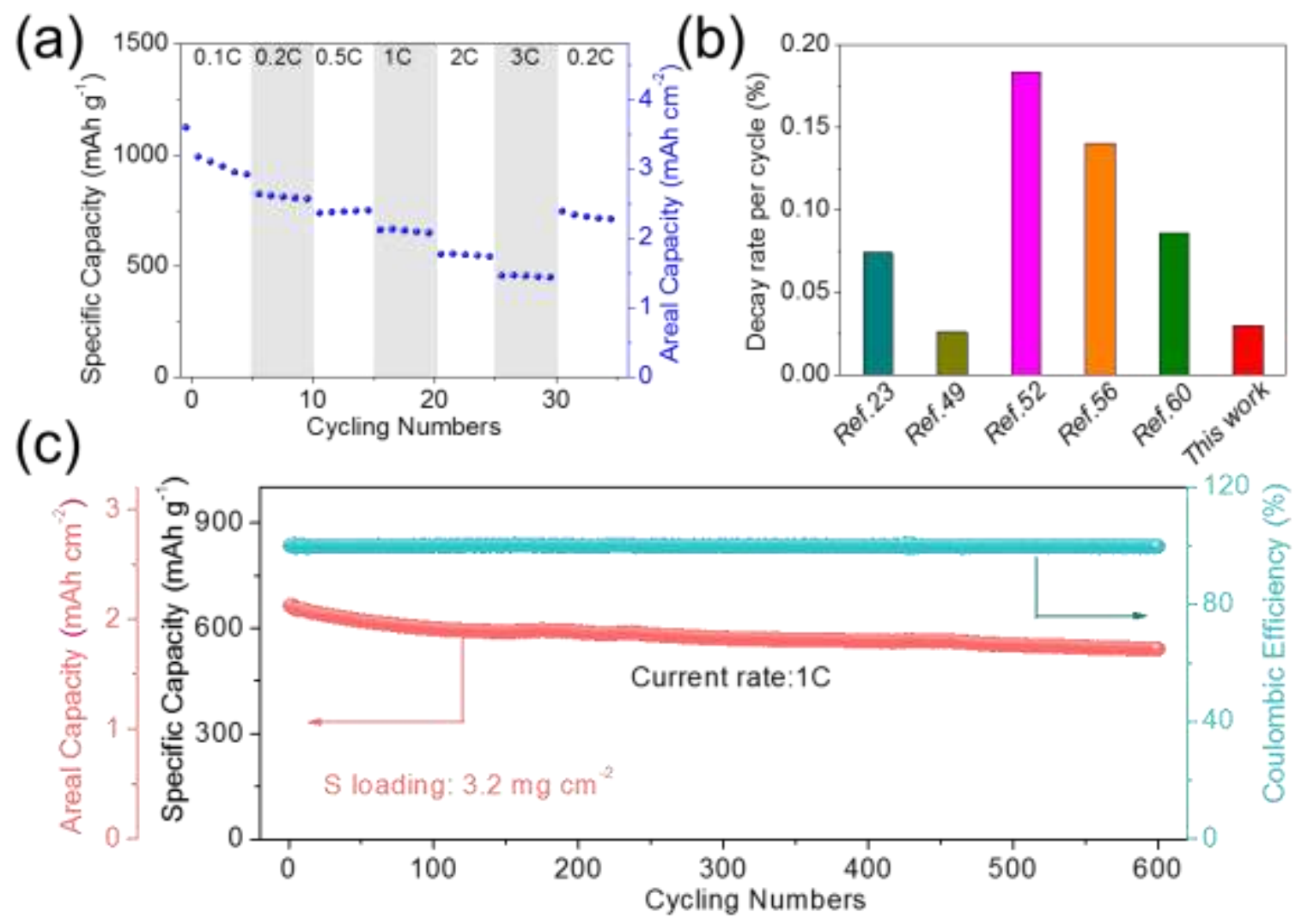

Figure 7. Performance of S@ZnSe/NHC with a high sulfur loading $\left(3.2 \mathrm{mg} \mathrm{cm}^{-2}\right)$ : (a) Rate performance. (b) Decay rate per cycle compared with reported works. (c) Cycling performance at $1 \mathrm{C}$. 
To meet the demand for high energy density of practical applications, LSBs should contain high sulfur loadings. Therefore, we studied the performance of $\mathrm{S} @ \mathrm{ZnSe} / \mathrm{NHC}$ cathodes at a higher sulfur loading of $3.2 \mathrm{mg} \mathrm{cm}^{-2}$. Figure $\mathrm{S} 26$ displays galvanostatic charge/discharge curves of $\mathrm{S} @ \mathrm{ZnSe} / \mathrm{NHC}$ cathodes at different current rates. Even at a high current rate of $3 \mathrm{C}$, the charge plateau and two discharge plateaus were also clearly observed, suggesting a low polarization during charge and discharge processes. At high S loading, S@ZnSe/NHC cathodes delivered a discharge capacity of $1125.72 \mathrm{mAh} \mathrm{g}^{-1}$ at $0.1 \mathrm{C}$ and $57.7 \mathrm{mAh} \mathrm{g}^{-1}$ at $3 \mathrm{C}$, which corresponded to areal capacities of 3.60 and $1.46 \mathrm{mAh} \mathrm{cm}^{-2}$, respectively (Figure 7a). The excellent rate performances could be attribute to high electrical conductivity and superior catalytic properties of ZnSe/NHC. Long-term cycling tests of S@ZnSe/NHC cathodes with 3.2 $\mathrm{mg} \mathrm{cm}{ }^{-2}$ of sulfur showed a discharge capacity of $540.5 \mathrm{mAh} \mathrm{g}^{-1}$ to be maintained after 600 cycles, with a $0.03 \%$ average capacity decay per cycle. Moreover, a high and steady CE above 99.8\% was also maintained after long-term cycling, demonstrating an excellent cycling stability (Figure 7c). Compared with other sulfur host materials reported in literatures, the S@ZnSe/NHC cathode showed a high electrochemical performance (Table S1)and lower decay rate per cycle compared with other works even at a high sulfur loading (Figure 7b). ${ }^{[23,50,55,59,63]}$

\section{Conclusions}

In summary, we rationally designed new LSBs cathodes based on $\mathrm{ZnSe} / \mathrm{NHC}$ sulfur hosts with dual effect adsorption and high catalytic activity. Their hollow nanoreactor geometry not only provide an accommodation for sulfur, but also integrates LiPS physical separation and chemical reaction in one cell towards high stable cyclability. ZnSe with sulfiphilic sites and NHC with lithiophilic sites, respectively, were confirmed by experimental results and DFT calculations, showing a strong LiPS adsorbability. Simultaneously, ZnSe nanoparticles could facilitate redox kinetics of LiPS conversion reaction during charge/discharge processes that were revealed by tremendous kinetic investigations, thus improving the sulfur utilization. These merits contribute to outstanding electrochemical performances of the LSBs with ZnSe/NHC as sulfur hosts. As a result, S@ZnSe/NHC cathode delivers excellent performances, including a reversible capacity of $540.5 \mathrm{mAh} \mathrm{g}^{-1}$ after 600 cycles at $1 \mathrm{C}$ at a relatively high sulfur loading of $3.2 \mathrm{mg} \mathrm{cm}^{-2}$. This work not only broadens the application of selenides materials in the field of LSBs, but also 
designs dual effect adsorptive nanoreactor serving as sulfur hosts, showing superior electrochemical properties for LSBs.

\section{Experimental Section}

Synthesis of zeolitic imidazolate framework (ZIF-8): $5.95 \mathrm{~g}(0.02 \mathrm{~mol})$ of $\mathrm{Zn}\left(\mathrm{NO}_{3}\right)_{2} \cdot 6 \mathrm{H}_{2} \mathrm{O}(98 \%$, Alfa Aesar) was dissolved in $150 \mathrm{~mL}$ methanol. The obtained solution was poured into $150 \mathrm{~mL}$ of a methanol solution containing $6.16 \mathrm{~g}(0.075 \mathrm{~mol})$ of 2-methylimidazole (99\%, Acros Organics) and the mixed solution was stirred for $24 \mathrm{~h}$ at room temperature. The obtained white precipitate was collected, washed with methanol several times and dried overnight.

Synthesis of ZnSe/NHC: $100 \mathrm{mg}$ of the as-obtained ZIF-8 powder and $250 \mathrm{mg}$ of selenium powder (99\%, Sigma Aldrich) were placed in two separated porcelain boats. The porcelain boats were placed within a tubular furnace having an Ar flow $\left(100 \mathrm{~mL} \cdot \mathrm{min}^{-1}\right)$, with the selenium boat upstream and the ZIF-8 powder downstream. The furnace was heated to $650{ }^{\circ} \mathrm{C}$ at a heating rate of $5^{\circ} \mathrm{C} \mathrm{min}{ }^{-1}$ and maintained at this temperature for $2 \mathrm{~h}$. After cooling to room temperature, the ZnSe/NHC powder was collected.

Synthesis of NHC: NHC was obtained by annealing ZIF-8 powder in the same conditions but without selenium. The obtained black powder was immersed in a $2 \mathrm{M} \mathrm{HCl}$ solution and stirred for $24 \mathrm{~h}$ to remove $\mathrm{Zn}$. The precipitate was collected by filtration, washed with ethanol and dried at $60{ }^{\circ} \mathrm{C}$ overnight.

Synthesis of S@ZnSe/NHC, S@NHC and S@Super P: Sulfur was incorporated by means of a simple melting diffusion process. To obtain S@ZnSe/NHC, as-prepared ZnSe/NHC and sublimed sulfur (99.98\%, Sigma Aldrich) were well mixed at a 1:3 weigh ratio and heated at $155^{\circ} \mathrm{C}$ for $12 \mathrm{~h}$ in a glass bottle under an Ar atmosphere. To remove the redundant sulfur outside of $\mathrm{ZnSe} / \mathrm{NHC}$, the powder was immersed in a $10 \mathrm{~mL} \mathrm{CS}_{2}$ and ethanol solution (1:4, volume ratio) for 10 min twice. For comparison, S@NHC and S@Super P (Super P from Alfa Aesar, 99\%) were obtained by the same process.

Materials Characterization: Chemical compositions were analyzed by X-ray diffraction (XRD) patterns recorded at room temperature using a Bruker AXS D8 Advance X-ray diffractometer with $\mathrm{Cu} \mathrm{K}$ radiation $(\lambda=1.5106 \AA$ ) operating at $40 \mathrm{kV}$ and $40 \mathrm{~mA}$. Field emission scanning electron microscopy (FESEM) analyses were carried on a ZEISS Auriga microscope with an energy dispersive X-ray spectroscopy (EDS) detector operating at $20 \mathrm{kV}$. Transmission electron 
microscopy (TEM) characterization was carried out on a Zeiss Libra 120 (Carl Zeiss, Jena, Germany) operating at $120 \mathrm{kV}$. High-resolution TEM (HRTEM) and scanning TEM (STEM) studies were carried out using a field emission gun FEI Tecnai F20 microscope at $200 \mathrm{kV}$ with a point-to-point resolution of $0.19 \mathrm{~nm}$. High angle annular dark-field (HAADF) STEM was combined with electron energy loss spectroscopy in the Tecnai microscope by using a Gatan Quantum filter. X-ray photoelectron spectroscopy (XPS) measurements were conducted at $150 \mathrm{~W}$ using a Phoibos 150 MCD-9 detector. Thermogravimetric measurements (TGA) were performed to record the ration of $\mathrm{S}$ within prepared composites. UV-vis absorption spectra were tested on a PerkinElmer LAMBDA 950 UV-vis spectrophotometer. Nitrogen adsorptiondesorption isotherms were measured to evaluate the specific surface area and the pore size distribution using a Brunauer-Emmett-Teller method (Tristar II 3020 Micromeritics system).

Electrochemical measurements: Working electrodes were prepared by mixing the active materials (S@ZnSe/NHC, S@NHC and S@Super P), Super P and PVDF binders with a weight ratio of 8:1:1 in N-methyl-2-pyrrolidone (NMP, 99.5\%, Acros Organics). Then the slurry was coated on an aluminum foil and dried at $60{ }^{\circ} \mathrm{C}$ under vacuum overnight. Subsequently, the coated aluminum foil was punched into small disks having a sulfur loading of about $1 \mathrm{mg} \mathrm{cm}^{-2}$ and were assembled into coin cells in an Ar-filled glovebox. Li foil was used as the counter electrode and Celgard 2400 membranes as separators. The electrolyte was prepared by dissolving 1.0 M lithium bis(trifluoromethanesulfonyl) imide (LiTFSI) (99\%, Acros Organics) in a mixture of 1,3-dioxolane (DOL, 99.5\%, Alfa Aesar) and dimethoxymethane (DME, 99\%, Honeywell) $(1: 1 \mathrm{v} / \mathrm{v})$ with the addition of $0.2 \mathrm{M} \mathrm{LiNO}_{3}(99.98 \%$, Alfa Aesar). The amount of electrolyte was about $20 \mu \mathrm{L}$ for each coin cell. Before cycling, all coin cells were aged for several hours to ensure a sufficient penetration of the electrolyte into the electrode. Galvanostatic charge/discharge (GCD) measurements were performed with a voltage window of 1.7-2.8 V vs. $\mathrm{Li}^{+} / \mathrm{Li}$ at different current densities using a Neware BTS4008 battery cycler. Cyclic voltammetry (CV) tests were performed on a battery tester BCS-810 from Bio Logic at different scan rate in the range of $0.1-0.4 \mathrm{mV} \mathrm{s}^{-1}$. Electrochemical impedance spectroscopy (EIS) tests were carried out using a sinusoidal voltage with amplitude of $10 \mathrm{mV}$ in the frequency range $100 \mathrm{kHz}$ to 0.01 $\mathrm{Hz}$.

Synthesis of $\mathrm{Li}_{2} \mathrm{~S}_{4}$ Solution and Adsorption Test: Sulfur and $\mathrm{Li}_{2} \mathrm{~S}$ (99.9\%, Alfa Aesar) with a molar ratio of 3:1 were added to appropriate amounts of DME and DOL (volume ratio of 1:1) 
under vigorous magnetic stirring overnight, until a dark brown solution was formed. For the polysulfide absorption ability test, $20 \mathrm{mg}$ active materials (ZnSe/NHC, NHC and Super P) were immersed into $3.0 \mathrm{~mL} 10 \times 10^{-3} \mathrm{M} \mathrm{Li}_{2} \mathrm{~S}_{4}$ solution, which was shaken and aged overnight. Symmetric Cell Assembly and Measurements: The ZnSe/NHC (NHC and Super P) composite was mixed with Super P and PVDF binder with a weight ratio of 8:1:1 in NMP. Then the slurry was coated onto the $\mathrm{Al}$ foil and dried at $60^{\circ} \mathrm{C}$ for $12 \mathrm{~h}$ in a vacuum oven. Two pieces of the same electrode (average loading about $0.5 \mathrm{mg} \mathrm{cm}^{-2}$ ) were used as identical working and counter electrodes. $40 \mu \mathrm{L}$ of electrolyte containing $0.5 \mathrm{M} \mathrm{Li}_{2} \mathrm{~S}_{6}$ and $1 \mathrm{M}$ LiTFSI dissolved in DOL/DME $(\mathrm{v} / \mathrm{v}=1 / 1)$ was added into each coin cell. $\mathrm{CV}$ measurements were performed at scan rate of 10 $\mathrm{mV} \mathrm{s}^{-1}$ and EIS tests were carried out in the frequency range $100 \mathrm{kHz}$ to $0.01 \mathrm{~Hz}$.

Measurement of Nucleation and Dissolution of $\mathrm{Li}_{2} \mathrm{~S}$ : Nucleation and dissolution of $\mathrm{Li}_{2} \mathrm{~S}$ were studied in standard 2032 coin cells. Equal amounts of ZnSe/NHC, NHC and Super P composites were dispersed in ethanol and then coated on carbon papers, which worked as the cathode. Li foil was used as the counter electrode. $20 \mu \mathrm{L}$ of $0.25 \mathrm{M} \mathrm{Li}_{2} \mathrm{~S}_{8}$ with $1.0 \mathrm{M}$ LiTFSI in tetraethylene glycol dimethyl ether solution was used as catholyte, and $20 \mu \mathrm{L}$ of a $1.0 \mathrm{M}$ LiTFSI solution without $\mathrm{Li}_{2} \mathrm{~S}_{8}$ was used as anolyte. Coin cells were held at $2.06 \mathrm{~V}$ to reduce the generation of higher order LiPS than $\mathrm{Li}_{2} \mathrm{~S}_{4}$. After that the cells were potentiostatically discharged at $2.05 \mathrm{~V}$

until current decreased to $10^{-5} \mathrm{~A}$. The dissolution of $\mathrm{Li}_{2} \mathrm{~S}$ was tested by assembling fresh coin cells, which were galvanostatically discharged at $0.10 \mathrm{~mA}$ until $1.80 \mathrm{~V}$, and subsequently galvanostatically discharged at $0.01 \mathrm{~mA}$ to $1.80 \mathrm{~V}$ for full transformation of $\mathrm{S}$ species into solid $\mathrm{Li}_{2} \mathrm{~S}$. Then cells were potentiostatically charged at $2.40 \mathrm{~V}$ for the dissolution of $\mathrm{Li}_{2} \mathrm{~S}$ into soluble LiPS until the charge current was below $10^{-5} \mathrm{~A}$.

\section{Supporting Information}

Supporting Information is available from the Wiley Online Library or from the author.

\section{Acknowledgements}

This work was supported by the European Regional Development Funds and by the Spanish Ministerio de Economíay Competitividad through the project SEHTOP, ENE2016- 77798-C4-3- 
R, and ENE2017-85087-C3. D. Yang and C. Zhang thank the China Scholarship Council for the scholarship support. J. Li obtained International Postdoctoral Exchange Fellowship Program (Talent-Introduction program) in 2019 and is grateful for the project (2019M663468) funded by the China Postdoctoral Science Foundation. Authors acknowledge funding from Generalitat de Catalunya 2017 SGR 327 and 2017 SGR 1246. ICN2 acknowledges the support from the Severo Ochoa Programme (MINECO, grant no. SEV-2017-0706) and is funded by the CERCA Programme/Generalitat de Catalunya. J. Llorca is a Serra Húnter Fellow and is grateful to MICINN/FEDER RTI2018-093996-B-C31, GC 2017 SGR 128 and to ICREA Academia program.

Received: ((will be filled in by the editorial staff))

Revised: ((will be filled in by the editorial staff)) Published online: ((will be filled in by the editorial staff))

\section{References}

[1]. A. Manthiram, Y. Fu, S. H. Chung, C. Zu, Y. S. Su, Chem. Rev. 2014, 114, 11751.

[2]. H.-J. Peng, J.-Q. Huang, X.-B. Cheng, Q. Zhang, Adv. Energy Mater. 2017, 7, 1700260.

[3]. Z. Li, H. B. Wu, X. W. Lou, Energy Environ. Sci. 2016, 9, 3061.

[4] H. J. Peng, J. Q. Huang, X. Y. Liu, X. B. Cheng, W. T. Xu, C. Z. Zhao, F. Wei, Q. Zhang, J. Am. Chem. Soc. 2017, 139, 8458.

[5] G. M. Zhou, L.-C. Yin, D.-W. Wang, L. Li, S. F. Pei, L. R Gentle, F. Li, H.-M. Cheng, ACS Nano 2013, 7, 5367.

[6] X. Ji, K. T. Lee, L. F. Nazar, Nat. Mater. 2009, 8, 500.

[7] C. Ye, L. Zhang, C. X. Guo, D. D. Li, A. Vasileff, H. H.Wang, S.-Z. Qiao, Adv. Funct. Mater. 2017, 27, 1702524.

[8] A. Manthiram, S. H. Chung, C. Zu, Adv. Mater. 2015, 27, 1980.

[9] J. Schuster, G. He, B. Mandlmeier, T. Yim, K. T. Lee, T. Bein, L. F. Nazar, Angew. Chem., Int. Ed. 2012, 51, 3591.

[10] M. Yu, R. Li, M. Wu, G. Shi, Energy Storage Mater. 2015, 1, 51.

[11] Z. Du, X. Chen, W. Hu, C. Chuang, S. Xie, A. Hu, W. Yan, X. Kong, X. Wu, H. Ji, L. J. Wan, J. Am. Chem. Soc. 2019, 141, 3977. 
[12] F. Xu, Z. Tang, S. Huang, L. Chen, Y. Liang, W. Mai, H. Zhong, R. Fu, D. Wu, Nat. Commun. 2015, 6, 7221.

[13] R. Fang, G. Li, S. Zhao, L. Yin, K. Du, P. Hou, S. Wang, H.-M. Cheng, C. Liu, F. Li, Nano Energy 2017, 42, 205.

[14] K. Mi, Y. Jiang, J. Feng, Y. Qian, S. Xiong, Adv. Funct. Mater. 2016, 26, 1571.

[15] S. Lu, Y. Cheng, X. Wu, J. Liu, Nano Lett. 2013, 13, 2485.

[16] L. Xia, S. Wang, G. Liu, L. Ding, D. Li, H. Wang, S. Qiao, Small 2016, 12, 853.

[17] H. J. Peng, G. Zhang, X. Chen, Z. W. Zhang, W. T. Xu, J. Q. Huang, Q. Zhang, Angew. Chem. Int. Ed. 2016, 55, 12990.

[18] X. Wang, G. Li, J. Li, Y. Zhang, A. Wook, A. Yu, Z. Chen, Energy Environ. Sci. 2016, 9, 2533.

[19] Z. Liang, G. Zheng, W. Li, Z. W. Seh, H. Yao, K. Yan, D. Kong, Y. Cui, ACS Nano 2014, 8, 5249 .

[20] L. Kong, B.-Q. Li, H.-J. Peng, R. Zhang, J. Xie, J.-Q. Huang, Q. Zhang, Adv. Energy Mater. 2018, $8,1800849$.

[21] C. Dai, L. Hu, M.-Q. Wang, Y. Chen, J. Han, J. Jiang, Y. Zhang, B. Shen, Y. Niu, S.-J. Bao, M. Xu, Energy Storage Mater. 2017, 8, 202.

[22] D. R. Deng, F. Xue, Y. J. Jia, J. C. Ye, C. D. Bai, M. S. Zheng, Q. F. Dong, ACS Nano 2017, 11,6031 .

[23] T. Chen, L. Ma, B. Cheng, R. Chen, Y. Hu, G. Zhu, Y. Wang, J. Liang, Z. Tie, J. Liu, Z. Jin, Nano Energy 2017, 38, 239.

[24] Z. Xiao, Z. Yang, L. Zhang, H. Pan, R. Wang, ACS Nano 2017, 11, 8488.

[25] C. Dai, J.-M. Lim, M. Wang, L. Hu, Y. Chen, Z. Chen, H. Chen, S.-J. Bao, B. Shen, Y. Li, G. Henkelman, M. Xu, Adv. Funct. Mater. 2018, 28, 1704443.

[26] H. Lin, L. Yang, X. Jiang, G. Li, T. Zhang, Q. Yao, G. W. Zheng, J. Y. Lee, Energy Environ. Sci 2017, 10, 1476.

[27] D. Liu, C. Zhang, G. Zhou, W. Lv, G. Ling, L. Zhi, Q. H. Yang, Adv. Sci. 2018, 5, 1700270.

[28] C. Zhang, J. J. Biendicho, T. Zhang, R. Du, J. Li, X. Yang, J. Arbiol, Y. Zhou, J. R. Morante, A. Cabot, Adv. Funct. Mater. 2019, 29, 1903842.

[29] Y. Tian, G. Li, Y. Zhang, D. Luo, X. Wang, Y. Zhao, H. Liu, P. Ji, X. Du, J. Li, Z. Chen, Adv. Mater. 2020, 32, e1904876. 
[30] H. Yuan, H.-J. Peng, B.-Q. Li, J. Xie, L. Kong, M. Zhao, X. Chen, J.-Q. Huang, Q. Zhang, Adv. Energy Mater. 2019, 9, 1802768

[31] Y. He, L. Wang, C. Dong, C. Li, X. Ding, Y. Qian, L. Xu, Energy Storage Mater. 2019, 23, 35 .

[32] Y. Zhang, W. Qiu, Y. Zhao, Y. Wang, Z. Bakenov, X. Wang, Chem. Eng. J 2019, 375, 122055.

[33] J. Xu, W. Zhang, H. Fan, F. Cheng, D. Su, G. Wang, Nano Energy 2018, 51, 73-82.

[34] A. Cabot, M. Ibáñez, P. Guardia, A. P. Alivisatos, J. Am. Chem. Soc. 2009, 131, 11326.

[35] M. Ibáñez, J. Fan, W. Li, D. Cadavid, R. Nafria, A. Carrete, A. Cabot, Chem. Mater. 2011, 23,3095 .

[36] S. Lu, T. Zhu, H. Wu, Y. Wang, J. Li, A. Abdelkader, K. Xi, W. Wang, Y. Li, S. Ding, G. Gao, R. V. Kumar, Nano Energy 2019, 59, 762.

[37] Q. Peng, Y. Dong, Y. Li, Angew. Chem. Int. Ed. 2003, 42, 3027.

[38] C. Dong, L. Guo, Y. He, C. Chen, Y. Qian, Y. Chen, L. Xu, Energy Storage Mater. 2018, 15 , 234.

[39] D. Su, K. Kretschmer, G. Wang, Adv. Energy Mater. 2016, 6, 1501785.

[40] Y. He, M. Luo, C. Dong, X. Ding, C. Yin, A. Nie, Y. Chen, Y. Qian, L. Xu, J. Mater. Chem. A 2019, 7, 3933.

[41] M. Wan, R. Zeng, K. Chen, G. Liu, W. Chen, L. Wang, N. Zhang, L. Xue, W. Zhang, Y. Huang, Energy Storage Mater. 2018, 10, 114.

[42] C. Dong, J. Liang, Y. He, C. Li, X. Chen, L. Guo, F. Tian, Y. Qian, L. Xu, ACS Nano 2018, 12,8277 .

[43] M. Mao, C. Cui, M. Wu, M. Zhang, T. Gao, X. Fan, J. Chen, T. Wang, J. Ma, C. Wang, Nano Energy 2018, 45, 346.

[44] Z. R. Ismagilov, A. E. Shalagina, O. Y. Podyacheva, A. V. Ischenko, L. S. Kibis, A. I. Boronin, Y. A. Chesalov, D. I. Kochubey, A. I. Romanenko, O. B. Anikeeva, T. I. Buryakov, E. N. Tkachev, Carbon 2009, 47, 1922.

[45] J. D. Wiggins-Camacho, K. J. Stevenson, J. Phys. Chem. C 2009, 113, 19082.

[46] Z. Li, J. Zhang, H. B. Wu, X. W. D. Lou, Adv. Energy Mater. 2017, 7, 1700281.

[47] J. Song, Z. Yu, M. L. Gordin, D. Wang, Nano Lett. 2016, 16, 864.

[48] X. Li, K. Ding, B. Gao, Q. Li, Y. Li, J. Fu, X. Zhang, P. K. Chu, K. Huo, Nano Energy 2017, 
40,655 .

[49] L. Hu, C. Dai, H. Liu, Y. Li, B. Shen, Y. Chen, S.-J. Bao, M. Xu, Adv. Energy Mater. 2018, 8, 1800709 .

[50] Y. Qiu, W. Li, W. Zhao, G. Li, Y. Hou, M. Liu, L. Zhou, F. Ye, F. Li, Z. Wei, S. Yang, W.

Duan, Y. Ye, Y. Guo, Y. Zhang, Adv. Mater. 2014, 14, 4281.

[51] M. Yan, H. Chen, Y. Yu, H. Zhao, C.-F. Li, Z.-Y. Hu, P. Wu, L. Chen, H. Wang, D. Peng, H.

Gao, T. Hasan, Y. Li, B.-L. Su, Adv. Energy Mater. 2018, 8, 1801066.

[52] L. Zhang, X. Chen, F. Wan, Z. Niu, Y. Wang, Q. Zhang, J. Chen, ACS Nano 2018, 12, 9578.

[53] B. Yuan, D. Hua, X. Gu, Y. Shen, L.-C. Xu, X. Li, B. Zheng, J. Wu, W. Zhang, S. Li, F. Huo, J. Energy. Chem. 2020, 48, 128.

[54] X. Li, B. Gao, X. Huang, Z. Guo, Q. Li, X. Zhang, P. K. Chu, K. Huo, ACS Appl. Mater. Interfaces 2019, 11, 2961.

[55] X. Zhu, W. Zhao, Y. Song, Q. Li, F. Ding, J. Sun, L. Zhang, Z. Liu, Adv. Energy Mater. 2018, 8, 1800201.

[56] Z. Yuan, H. J. Peng, T. Z. Hou, J. Q. Huang, C. M. Chen, D. W. Wang, X. B. Cheng, F. Wei, Q. Zhang, Nano Lett. 2016, 16, 519-27.

[57] G. Zhou, H. Tian, Y. Jin, X. Tao, B. Liu, R. Zhang, Z. W. Seh, D. Zhuo, Y. Liu, J. Sun, J. Zhao, C. Zu, D. S. Wu, Q. Zhang, Y. Cui, Proc. Natl. Acad. Sci. USA 2017, 114, 840.

[58] A. Berger, A. T. S. Freiberg, A. Siebel, R. Thomas, M. U. M. Patel, M. Tromp, H. A. Gasteiger, Y. Gorlin, J. Electrochem. Soc. 2018, 165, A1288.

[59] S. Huang, Y. V. Lim, X. Zhang, Y. Wang, Y. Zheng, D. Kong, M. Ding, S. A. Yang, H. Y. Yang, Nano Energy 2018, 51, 340.

[60] C.-Y. Fan, Y.-P. Zheng, X.-H. Zhang, Y.-H. Shi, S.-Y. Liu, H.-C. Wang, X.-L. Wu, H.-Z. Sun, J.-P. Zhang, Adv. Energy Mater. 2018, 8, 1703638.

[61] D. Su, M. Cortie, H. Fan, G. Wang, Adv. Mater. 2017, 29, 1700587.

[62] Z. Guo, H. Nie, Z. Yang, W. Hua, C. Ruan, D. Chan, M. Ge, X. Chen, S. Huang, Adv. Sci. 2018, 5, 1800026.

[63] M. Yu, J. Ma, H. Song, A. Wang, F. Tian, Y. Wang, H. Qiu, R. Wang, Energy Environ. Sci. 2016, $9,1495$. 